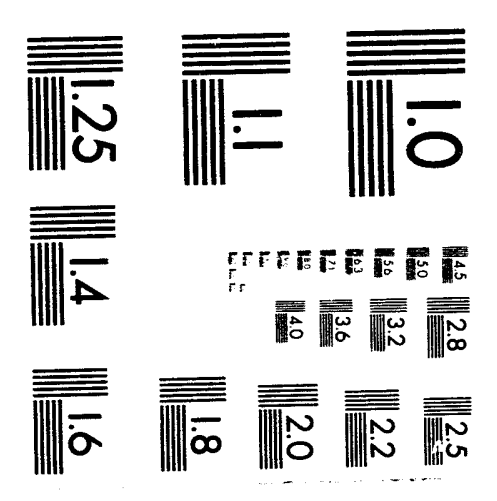



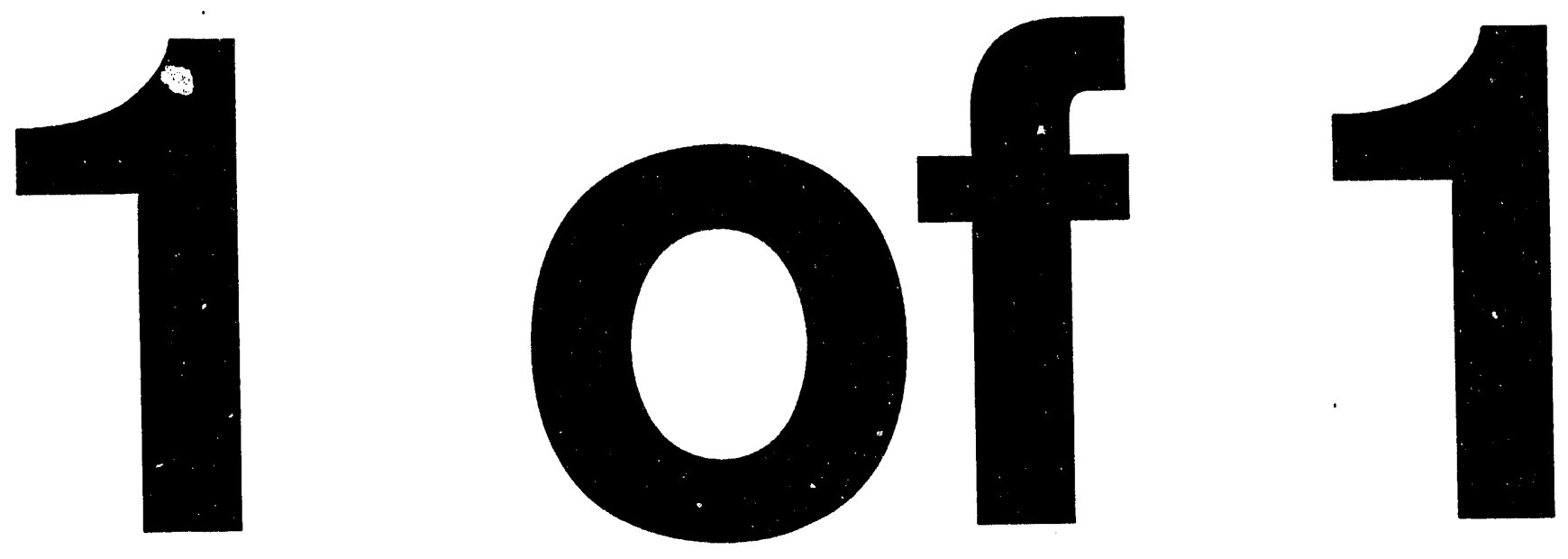


\title{
THE LOS ALAMOS NATIONAL LABORATORY PRECISION DOUBLE CRYSTAL SPECTROMETER
}

by

Dane V. Morgan

\section{Carlos J. Stevens}

Robert J. Liefeld

\section{DISCLAIMER}

\begin{abstract}
This report was prepared as an account of work sponsored by an agency of the United States Government. Neither the United States Government nor any agency thereof, nor any of their employees, makes any warranty, express or implied, or assumes any legal liability or responsibility for the accuracy, completeness, or usefulness of any information, apparatus, product, or process disclosed, or represents that its use would not infringe privately owned rights. Reference herein to any specific commercial product, process, or service by trade name, trademark, manufacturer, or otherwise does not necessarily constitute or imply its endorsement, recommendation, or favoring by the United States Government or any agency thereof. The views and opinions of authors expressed herein do not necessarily state or reflect those of the United States Government or any agency thereof.
\end{abstract}




\section{OUTLINE}

I. INTRODUCTION

A. Motivation for Construction of the Instrument

B. A Brief History of the Instrument

II. INSTRUMENT DESCRIPTION

A. Mechanical Systems

1. Overall Mechanical Description of the Instrument

2. Alignment Procedure

B. Motion Control Systems

1. Stepper Motors

2. Inchworm Motors

C. Computer Control System

D. Vacuum System

III. OPERATING INSTRUCTIONS

A. Alignment Program

B. Scan Programs

1. Scan Sequence $(n, n)$

2. Rocking Curves (n,-n)

IV. OBSERVATIONS OF THE COPPER K $\alpha$ LINES

A. X-ray Tube

B. Raw Spectrum and Rocking Curves

V. CHARACTERISTICS AND SPECIFICATIONS

A. Comparison of LANL P-14 Specifications and Actual Achieved Specifications

B. Future Work

1. Achieving the Design Specifications

2. Correction of Idiosyncrasies

VI. FOOTNOTES

VII. BIBLIOGRAPHY

VIII. APPENTDIX 


\section{LIST OF FIGURES}

1. PDCS Plan View

2. $\mathrm{AA}$ and 2OA Alignment for Coaxiality and Parallelism

3. OB Alignment for Parallelism

4. System Operation and Control

5. PDCS Vacuum System

6. Main Menu Display

7. X-ray Tube

8. $\quad K \alpha_{1,2}$ Spectrum

9. Rocking Curve 


\section{INTRODUCTION}

\section{Motivation for the Construction of the Insmument}

$X$-ray spectroscopy is an important tool for the experimental study of atomic physics and materials science, and a fully automated vacuum double crystal spectrometer is a versatile instrument for research in these fields. Desirable features of the instrument include the total automation of the $x$-ray spectrometer positioning and data acquisition. This saves many man-hours compared to labor-intensive manual $x$-ray spectrometers, and eliminates the possibility of human error. Another desirable feature of the instrument is the ability to observe the entire $x$-ray spectrum, including soft and ultra-soft $x$-rays, so the instrument must be equipped with a high-vacuum capability. Accuracy and resolution are the most important characteristics that we wish to incorporate into the instrument. The double crystal spectrometer is the best instrument for this type of work because of our ability to measure rotational positions of the crystals with great precision, and because it has an inherently low level of scattered background intensity.

X-ray spectroscopists at the Los Alamos National Laboratory (LANL) have stated that the theories of atomic structure and material properties have advanced to the point where existing measurements of atomic emission line wavelengths are inadequate, so there is a need for an instrument which can more accurately measure these wavelengths. Ultrapure and perfect silicon crystals are now available which can measure wavelengths accurately to approximately one part-per-million. The wavelength accuracy can be converted to the spectrometer's angular accuracy using Bragg's law,

$$
\mathrm{n} \lambda=2 \mathrm{~d}(\sin \theta)
$$

and

$$
\mathrm{d} \lambda \lambda=(\cot \theta) \mathrm{d} \theta
$$

A wavelength accuracy of one part-per-million therefore corresponds to an angular accuracy of $5 \times 10^{-7}$ radians (or 0.1 arc seconds) at $26.5^{\circ}$. By measuring standard wavelengths, such as molybdenum $\mathrm{K} \alpha$, with a precision double crystal spectrometer equipped with silicon crystals, the d-spacing of other crystals can be precisely determined by measuring the Bragg angle of the reflection of the standard wavelength. By extending 
this process, it would be possible to accurately determine the $\mathrm{x}$-ray emission wavelengths and absorption edges of all the elements in the periodic chart.

Not all crystals are necessarily suitable for use in precision spectroscopy, and for those crystals that are suitable, the accuracy of the instrument is limited by the purity, quality, and other properties of the crystal. The precision double crystal spectrometer can characterize crystal properties by measurement of the crystal diffraction width in the parallel (rocking curve) position. Rocking curve widths fall in the range of 0.1 to 100 arc seconds, full-width-at-half-maximum (FWHM), with the narrow rocking curve widths occurring for the $\mathrm{x}$-ray energies of the $\mathrm{K}$ spectra of heavy atoms. It is therefore desirable to have an instrument with a resolution on the order of 0.01 arc seconds to accurately plot high energy rocking curve profiles.

There are many difficulties in the design and construction of an instrument with an angular accuracy of $0.1 \mathrm{sec}$. and an angular resolution of $0.01 \mathrm{sec}$. Thermal gradients and vibrations can have a profound effect on the ability to achieve these specifications. Moore Special Tool Company was first contracted to design and build the instrument because of their experience and reputation with precision metrology.

\section{A Brief History of the Instrument}

The nitial design contract for the Precision Double Crystal Spectrometer (PDCS) was awarded to Moore Special Tool Co. (MST) in April 1986, based on LANL P-14 PDCS Specifications. Shortly thereafter, MST began constructing the PDCS. In July 1989, MST terminated work on the PDCS, and shipped the unfinished subassemblies to NSLS. The PDCS was then shipped to LANL for evaluation by MEC-6 division.

In the summer of 1990, the N.M.S.U. Physics Department was contracted by LANL to render the PDCS operational, and all the unfinished subassemblies were shipped to Las Cruces, NM. An initial assessment was made to determine which subassemblies could be completed locally, and which subassemblies would be completed by subcontractors. The decision was made to have MST complete the precision bearings for the $\Theta A, \Theta B$, and $28 A$ axes, and to design and build the 120 t.p.i. micrometer lead screw and fine motion drive for the $2 \Theta \mathrm{A}$ axis. All other work would be accomplished locally, including design and construction of the $20 \mathrm{~B}$ spindle and detector arm, inchworm mounts, 28A lift-lock, and crystal holders. All other major subassemblies were essentially complete.

The completed subassemblies from MST were received in August 1991. At about the same time, a Manson proportional counter was received from Los Alamos for use as the 
detector. At N.M.S.U., a sustained effort was made to develop the software required to operate the inchworm motors, Compumotors, and data acquisition. The subassemblies built in Las Cruces were completed, and the final assembly of the PDCS was begun.

The alignment of the instrument was performed as the instrument was assembled. The $\Theta A$ axis was aligned for coaxiality and parallelism with respect to the $2 \Theta A$ axis, and the $\boldsymbol{O A}$ and $\mathrm{OB}$ axes were made parallel. The two quartz crystals were aligned so their optical faces were parallel and coaxial to their respective axes. The alignment procedure will be described in greater detail later in the report.

The inchworm motors and controller proved to be a major obstacle to the construction of the instrument. The inchworm system was received with a faulty Heidenhain EXE encoder electronics box, a bad inchworm motor, and faulty cabling. These problems were corrected, one by one, and in June 1992, the construction of the PDCS was complete, and testing of the operational programs was begun.

In order to test the PDCS, a copper $x$-ray source was attached to the PDCS vacuum chamber. The copper $\mathrm{K} \alpha$ and $\mathrm{K} \beta$ emission spectrum was observed and recorded as the PDCS scanned in the $(1,1)$ dispersive mode. The PDCS was then placed in the $(1,-1)$ position, and a rocking curve at the copper $K \alpha$ wavelength was recorded. The spectrometer motion and data acquisition were fully automated during these tests, and the only operator action required was to enter the initial scan parameters.

After initial x-ray testing of the PDCS, work began on the vacuum system. The chamber was pumped down to $10^{-2}$ torr by a mechanical forepump, and checked with a helium leak detector. A turbopump, controller, and a special elbow were acquired from LANL. After evacuating the vacuum chamber to $10^{-2}$ torr, the turbopump further reduced the ultimate pressure in the vacuum chamber to $2 \times 10^{-6}$ torr, as measured by an ionization gauge. 


\title{
INSTRUMENT DESCRIPTION
}

\author{
Mechanical Systems
}

\section{Overall Mechanical Description of the Instrument}

The PDCS, shown in Fig. 1, is supported by a cast iron base plate designed for minimum deformation in a high vacuum environment. The base plate supports both the spectrometer and the vacuum chamber. It was originally intended for the spectrometer to be supported by a Barry air support system to dampen mechanical vibrations, but this air support system is not presently being used because of the lack of clearance between the hoist and the top of the vacuum chamber in Gardiner Hall room 60, where the spectrometer presently resides.

The 2ӨA axis rests on the center of the base plate, and supports the rest of the instrument. The 20A axis is comprised of two rotational subassemblies: an Ultradex 720 indexing table provided by A. A. Gage, and a precision bearing fabricated by MST, which serves as a fine angle divider. The indexing table provides a $360^{\circ}$ rotational capability in discrete increments of $0.5^{\circ}$, and each of these 720 positions is accurate to \pm 0.125 arc seconds. A lift/lock mechanism and a $360^{\circ}$ rotational drive are used to move the indexing table to the desired position. The indexing table rides on top of the precision bearing, which provides fine motion capability for the $2 \theta \mathrm{A}$ axis. A tangent arm is mounted on the upper bearing plate of the precision bearing. This tangent arm is driven by a $120 \mathrm{t}$. p. i. lead screw, which is, in turn, driven by a stepper motor, providing fine motion of the $2 \theta \mathrm{A}$ axis in increments of 0.1 arc seconds over a $0.5^{\circ}$ range.

The yoke is mounted to the top of the Ultradex 720 indexing table, and is centered on the table with a guide pin. The purpose of the yoke is to provide a rigid support for the $\Theta A$ and $\Theta B$ crystal axes, as well as the $2 \theta B$ detector axis. The $\Theta A$ and $\Theta B$ axes are mounted on the lower horizontal portion of the yoke, and support the crystal holders and crystals. The $\Theta \mathrm{A}$ and $\mathrm{OB}$ crystal axes are identical, and function in a manner similar to the $2 \theta \mathrm{A}$ axis. Rotations are performed by the combination of a MST 1440 indexing table and a precision bearing. The MST 1440 tables are capable of $360^{\circ}$ rotations in discrete steps of $0.25^{\circ}$, with an angular uncertainty of \pm 0.125 arc seconds at each angular position. The 1440 tables can be rotated by the combination of a lift/lock mechanism and a $360^{\circ}$ rotary drive mechanism. The 1440 indexing tables ride on precision bearings, also fabricated by MST, which serve as fine angle dividers. Tangent arms, mounted on the upper precision bearing plates, are driven by Burleigh inchworm motors, providing the fine angular motion 

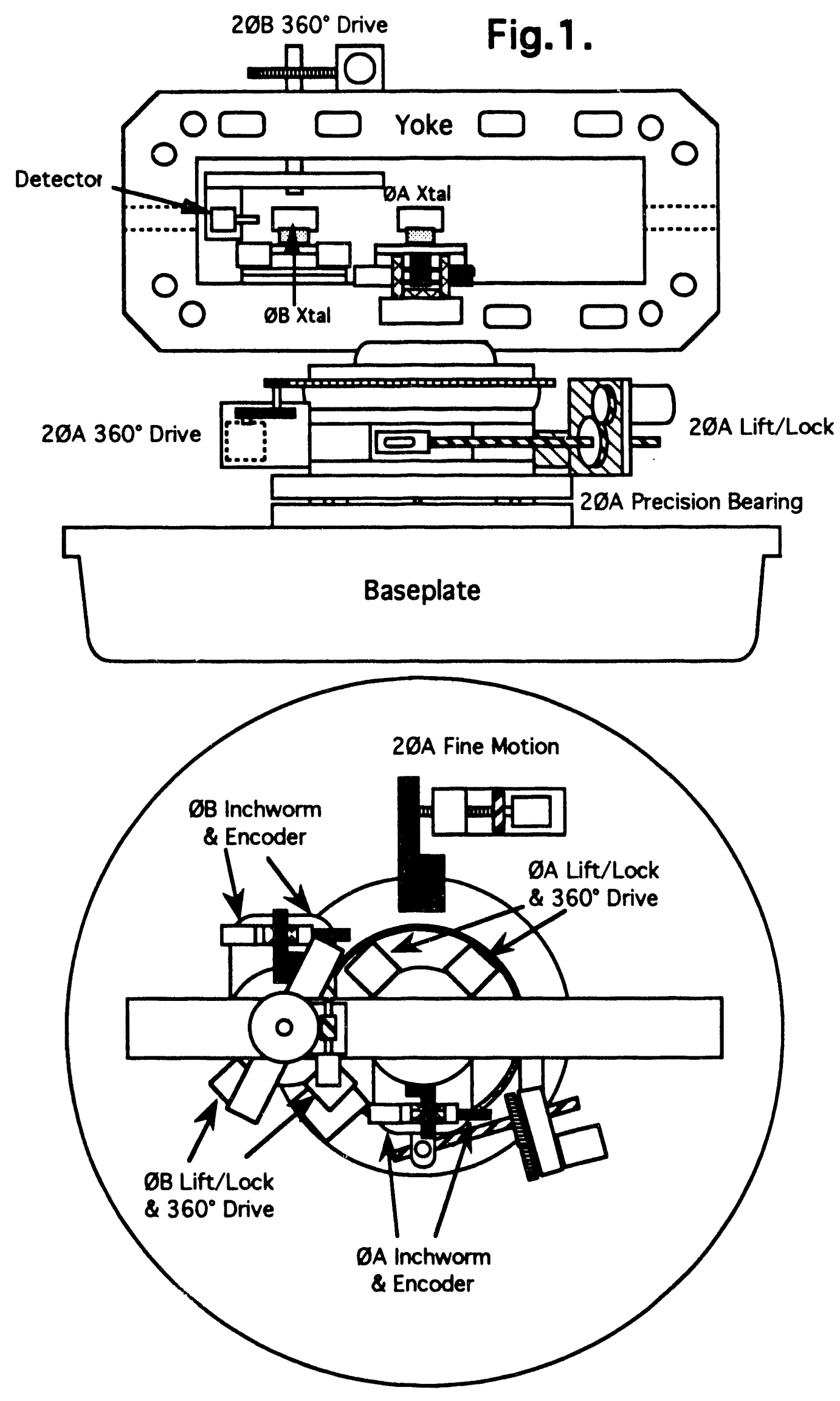
for the $\Theta \mathrm{A}$ and $\mathrm{OB}$ axes. These axes are thus capable of $360^{\circ}$ rotations in discrete angular steps of 0.1 arc seconds.

The 2OB axis is mounted on the upper horizontal extension of the yoke, and is responsible for the correct positioning of the $x$-ray detector. This axis is parallel and coaxial to the $\mathrm{OB}$ axis. A stepper motor is used to drive a worm, which in turn drives a worm gear mounted on an aluminum shaft. The gears are preloaded by spring tension. The aluminum shaft extends through a hole in the yoke, and is supported by a thrust bearing, allowing rotation about the $2 \Theta \mathrm{B}$ axis. The Manson $\mathrm{x}$-ray detector is mounted facing the $2 \theta \mathrm{B}$ axis on a level aluminum channel, which is connected to the aluminum shaft. This axis can be rotated through a full $360^{\circ}$ angle in discrete steps of 18 arc seconds.

\section{Alignment Procedure}

Several alignments must be performed for the PDCS to function as a precision instrument, and our ability to perform accurate alignments directly afferts the precision capabilities of the instrument. In general, the A and B axes must be parallel, and the plane of dispersion will be defined as the plane perpendicular to the A and B axes. The Bragg planes of the $A$ and $B$ crystals must be aligned parallel to the axes of rotation, and the $x$-ray beam must be parallel to the plane of dispersion. The $\Theta \mathrm{A}, \Theta \mathrm{B}$, and $2 \Theta \mathrm{A}$ axes all use tangent arms with linear actuators for the small angle rotations. These systems must be aligned and calibrated in order to measure the small angles accurately.

The first step in the alignment procedure is to make the $2 \theta \mathrm{A}$ and $\Theta \mathrm{A}$ axes parallel and coaxial. The set-up for these alignments is shown in Fig. 2. Both the coaxiality and parallelism of the $2 \Theta \mathrm{A}$ and $\Theta \mathrm{A}$ axes must be checked after an adjustment has been made. The alignment checks should only be performed with both the $\Theta \mathrm{A}$ and $2 \Theta \mathrm{A}$ indexing tables in the locked position, and with the $\Theta \mathrm{A}$ and $2 \Theta \mathrm{A}$ fine motion bearings engaged (lifting jacks lowered). The auto-collimator and diagonal mirror should be held in fixed positions independent of the spectrometer.

To obtain parallelism between the $\Theta \mathrm{A}$ and $2 \Theta \mathrm{A}$ axes, we must first align the autocollimator axis and the $2 \Theta \mathrm{A}$ axis. Adjustment of the optical flat located on the $\Theta \mathrm{A}$ indexing table top may be necessary to ensure that the optical flat is parallel to the 2OA plane of rotation. Optical wax was used to hold the optical flat to the top of the $\Theta \mathrm{A}$ indexing table. If the optical flat was misaligned with respect to the $2 \theta \mathrm{A}$ axis, circular motion of the autocollimator image was observed as the $2 \theta \mathrm{A}$ axis was rotated, with the $\Theta \mathrm{A}$ axis fixed. After the optical flat was made parallel to the $2 \theta \mathrm{A}$ axis, the $\Theta \mathrm{A}$ axis was rotated while the autocollimator and $2 \theta \mathrm{A}$ axis were held fixed. A circular notion of the autocollimator image 


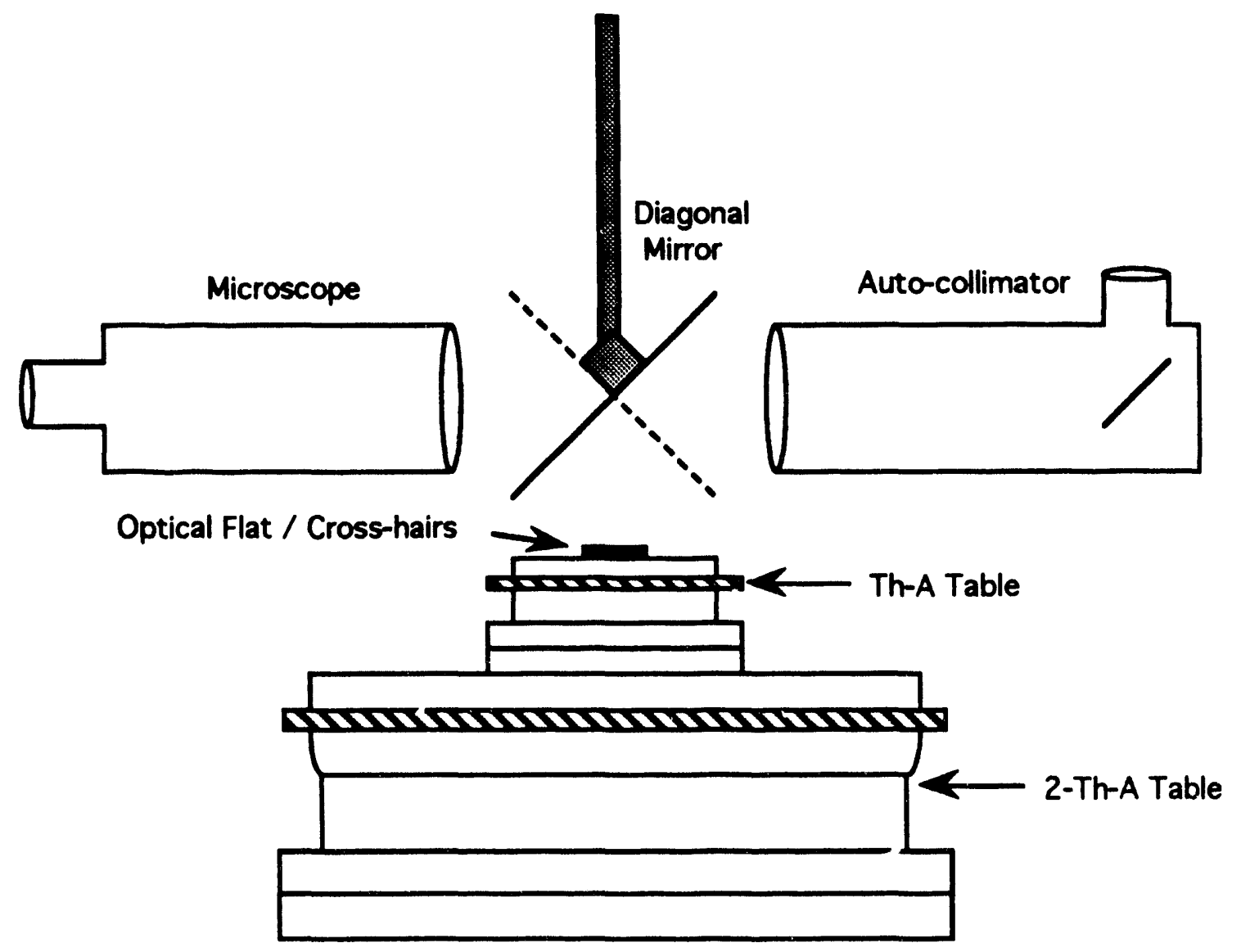

Fig. 2. Alignment Configuration for $\Theta A, 2 \Theta A$ parallelism, and $\Theta A, 2 \Theta A$ coaxiality.

indicated that the $\Theta \mathrm{A}$ and $2 \theta \mathrm{A}$ axes were misaligned. The $\Theta \mathrm{A}$ axis was then shimmed between the yoke and the precision bearing until the auto-collimator image remained fixed. The accuracy of this alignment is limited by the resolution of the auto-collimator image, however, the alignment was repeatable within approximately 1 arc second.

The optical flat was removed from the top of the $\Theta A$ indexing table, and a set of cross-hairs were placed on the table. The cross-hairs were observed through a microscope, and centered with respect to the $\Theta \mathrm{A}$ axis. This was accomplished by moving the crosshairs until the reference point determined by the intersection of the cross hairs remained fixed as the $\Theta A$ axis was rotated. The $\Theta A$ axis was then held fixed, while the $2 \Theta \mathrm{A}$ axis was rotated. A circular motion of the cross-hairs indicated that the $\Theta A$ and $2 \theta A$ axes were not coaxial. The $\Theta \mathrm{A}$ axis was translated with respect to the yoke until the $\Theta \mathrm{A}$ and $2 \theta \mathrm{A}$ axes were coaxial, and the parallelism alignment was rechecked. The seven $\mu \mathrm{m}$ width of the cross-hairs provides a good estimate for the uncertainty of the coaxial alignment. 
Now that the $\Theta \mathrm{A}$ and $2 \theta \mathrm{A}$ axes have been aligned for parallelism and coaxiality, the $\Theta B$ axis must be aligned parallel to the $\Theta A$ and $2 \theta A$ axes, and coaxial to the $2 \theta B$ axis. The alignment set-up is shown in Fig. 3. Optical flats are placed in the crystal holders such that reflections off both the front and back of the optical flats are possible. The optical flat is aligned parallel to its axis of rotation by observing the auto-collimator image reflected by the front of the optical flat. The $\Theta A$ indexing table is lifted, rotated $180^{\circ}$, and locked, and the auto-collimator image is observed from the back of the optical flat. The crystal holder is then tilted until the auto-collimator alignment is the same for both the front and back of the optical flat, making the optical flat parallel to the axis of rotation. The auto-collimator axis can now easily be aligned parallel to the plane of dispersion.

The optical flat is then removed from the $\mathrm{OA}$ crystal holder, while care is taken to ensure that the auto-collimator is not moved. The auto-collimator image for reflections off the $\Theta B$ axis optical flat is then located. The $\Theta B$ axis is rotated $180^{\circ}$ to observe reflections off the back of the optical flat, and the $\mathrm{OB}$ axis crystal holder is rotated through its horizontal axis so that both the front and back optical reflections can be observed with the auto-collimator. The addition of shims of the $\mathrm{OB}$ axis between the yoke and the lower plate of the $\mathrm{OB}$ precision bearing may be needed to accomplish this alignment. The completion of this alignment indicates that the $\mathrm{OB}$ axis optical flat is parallel to the axis of rotation, and that the $\mathrm{OA}$ and $\mathrm{\Theta B}$ axes are parallel with respect to the yoke axis.

We must also ensure that the $\mathrm{OA}$ and $\mathrm{OB}$ axes are parallel with respect to a $90^{\circ}$ angle relative to the yoke axis. The auto-collimator is now placed in position 2 of Fig. 3, and the optical flat in the $\mathrm{OA}$ axis crystal holder is adjusted so that it is parallel to the $\mathrm{OA}$ axis of rotation as described previously. A large optical flat is attached to the yoke, and is adjusted so that it is parallel to the $\Theta \mathrm{A}$ optical flat. The auto-collimator is now moved to position 3 in Fig. 3, and parallelism of the $\mathrm{OB}$ axis optical flat was checked for parallelism with the image from the large optical flat, adding shims if necessary. This completes the alignment procedure for parallelism of the $2 \theta \mathrm{A}, \Theta \mathrm{A}$, and $\Theta \mathrm{B}$ axes.

The $2 \Theta B$ and $\Theta B$ axes were also checked for coaxiality. A dial indicator was attached to a special extension of the $2 \theta \mathrm{B}$ detector arm. The dial indicator was placed against the circular edge of the indexing table, and the run-out was measured as the $2 \theta \mathrm{B}$ axis was rotated around the $\mathrm{OB}$ axis. The uncertainty of this coaxiality measurement is estimated to be the approximately the least count on the dial indicator, which is 0.001 inches. The parallelism of the $\mathrm{OB}$ axis with respect to the $\mathrm{OA}$ and $28 \mathrm{~A}$ axes must be rechecked to ensure that translation of the $\Theta B$ axis has not affected the alignment for parallelism. 


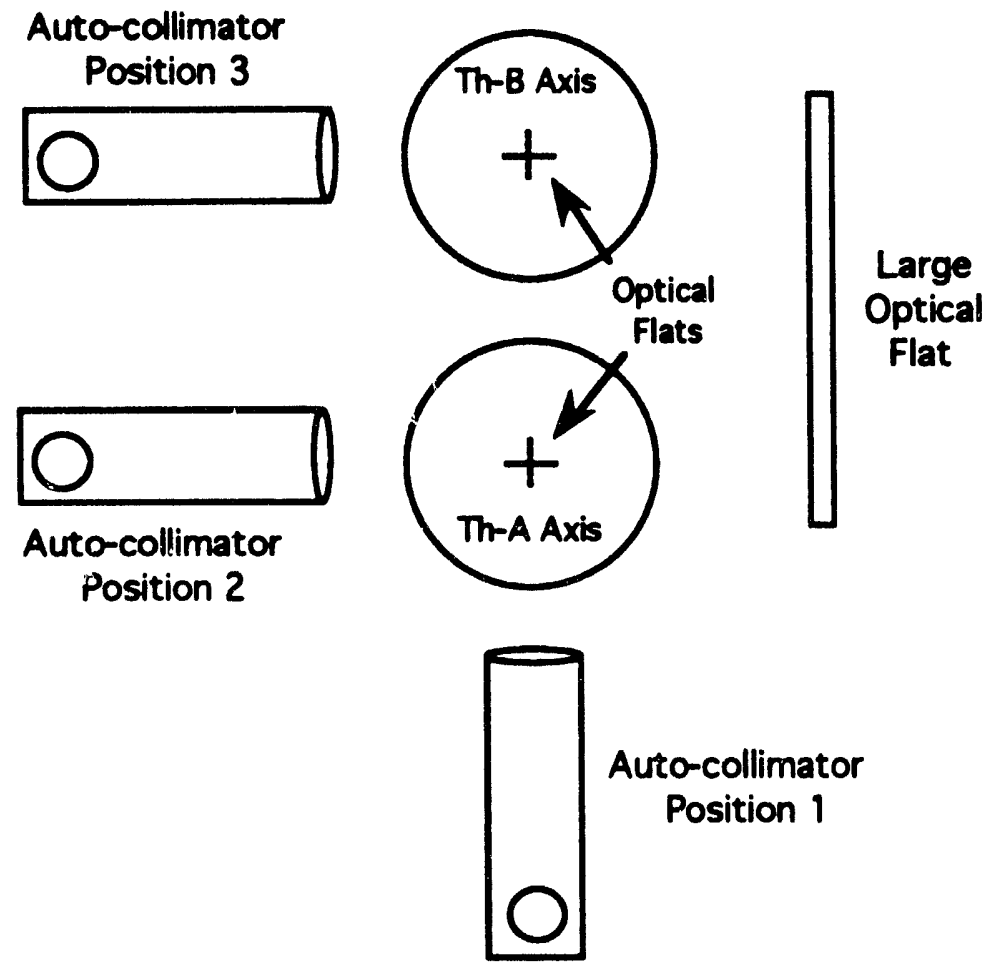

Fig. 3. Alignment Set-up for $Q A, Q B$ parallelism.

\section{Motion Control Systems}

\section{Stepper Motors}

A total of eight stepper motors are used to perform various motion control functions for the PDCS. Two high-torque six-amp vacuum compatible stepper motors are used to operate the operate the $28 \mathrm{~A}$ lift/lock mechanism and the $28 \mathrm{~A} 360^{\circ}$ drive assembly. The remaining six stepper motors are smaller three-amp vacuum compatible stepper motors which run the $\Theta A$ and $\Theta A$ lift-lock mechanisms, the $\Theta A$ and $\Theta B$ 360 drive assemblies, the $20 \mathrm{~B} 360^{\circ}$ drive assembly, and the 28A fine motion drive assembly. Each motor is accompanied by an AL drive, which provides the power and the control signals to the stepper motors. Two Compumotor $\mathbf{3 0 0 0}$ indexers are programmed to control the eight stepper motors. The indexers can be operated by either local or remote control.

Precautions must be taken to prevent the three indexing tables from being rotated while they are in the locked position. This is accomplished by microswitches which are closed when the tables are in the lifted position. The $360^{\circ}$ drive motors can then be 
operated to rotate their respective axes. If the tables are in the locked position, the interlock is open and the $360^{\circ}$ drive is inoperative. The interlock microswitches also provide a TTL logic level command to the $\mathbf{3 0 0 0}$ indexer. The purpose of this command is to ensure the tables can only be lifted if they are in the locked position and visa versa.

Temperature stability is important to the precision capabilities of the instrument, and the motor temperatures can warm to approximately $50^{\circ} \mathrm{C}$ when left on for extended periods of time. To avoid running the motors continuously, it is possible to use the shutdown command to shut off power to the motor. The motor will remain fixed in one of the $\mathbf{2 0 0}$ magnetic detents that exist in the $360^{\circ}$ motor rotation. The Compumotor controllers are programmed to move the motor to one of its detent positions, and then shutdown the motor. Each motor has a running time of a few seconds, and there is no appreciable rise in motor temperature.

\section{Inchworm Positioning System}

The PDCS utilizes two Burleigh model IW-700-10 vacuum compatible inchworm motors to obtain fine motion in the $\Theta \mathrm{A}$ and $\mathrm{\Theta B}$ axes. The motors drive a tangent arm mounted on the upper precision bearing plate of the respective axis. Heidenhain electrooptical encoders are used to sense the position of the tangent arm, and these feedback signals are amplified and processed by the two Heidenhain model EXE-702 electronics units. The entire inchworm positioning system is controlled by a Burleigh 7000 controller, which is linked to the computer through the IEEE-488 interface. The controller reads the positioning orders from the computer, and directs the inchworm motors to move towards the desired position. The encoder network measures the change in position, and tells the controller when the system is correctly positioned. The controller then orders the inchworm motors to stop, and the feedback loop holds the inchworms in the desired position. For a more complete description of the inchworm motors, controller and encoder system, the reader is referred to the appropriate technical manuals.

For the fine positioning systems that uses the combination of a tangent arm and a translational positioning system, it is important to have the tangent arm and the encoder head aligned perpendicular to each other. The angular rotation of the axis, $\theta$, is related to the inchworm distance of travel, $x$, by the equation

$$
\Theta=\tan ^{-1}(x / a)
$$


where $a$ is the fixed distance between the inchworm translational centerline and the rotational axis. Using the Taylor Series expansion, we have

$$
\theta=(x / a)-1 / 3(x / a)^{3}+O(x / a)^{5}
$$

In order to meet the requirement that $\boldsymbol{\theta}$ have an angular accuracy of 0.1 seconds of arc, we must have

$$
1 / 3(\mathrm{x} / \mathrm{a})^{3}<5 \times 10^{-7},
$$

or

$$
|x / a|<0.0114 \cong 0.65^{\circ}
$$

Since $0.25^{\circ}$ of total rotation is required for the $\mathrm{OA}$ and $\Theta \mathrm{B}$ fine motion, and $0.50^{\circ}$ of total rotation is required for the $28 \mathrm{~A}$ axis, the tangent arms must be closely perpendicular to the centerline of the translational device.

The inchworm and encoder system can be programmed to move in discrete steps of $0.1 \mu \mathrm{m}$. This can be converted to least count angular accuracy by

$$
\mathbf{Q}=\mathbf{x} / \mathbf{a}
$$

and

$$
\delta \theta=(1 / a) \delta x
$$

For $\mathrm{a}=20.6265 \mathrm{~cm}$ for the $\mathrm{QA}$ and $\mathrm{QB}$ tangent arm lengths, a step of $0.1 \mu \mathrm{m}$ in inchworm travel corresponds to a rotational motion of 0.1 arc seconds. To obtain $0.25^{\circ}$ of total rotation, 9000 discrete inchworm positions are required. To maintain 0.1 arc seconds of absolute accuracy over the entire range of travel, the tangent arm length must be made accurate to approximately one part in 20,000 , or

$$
a=20.6265 \pm 0.0010 \mathrm{~cm}
$$

Alternatively, the tangent arm length may be made arbitrary, and calibration data in the form of number of discrete inchworm steps per quarter degree of angular motion can be placed in 
the computer program. The calibration data is obtained by observing the autocollimator image from an optical flat on the table, and counter-rotating the indexing table and the fine motion subassembly for the appropriate axis by $0.25^{\circ}$. This is the method presently being used.

In order to obtain an angular resolution of 0.01 arc seconds, which is the desired resolution for high-energy rocking curves, the inchworm must be capable of making discrete translational steps of $0.01 \mu \mathrm{m}$. This is beyond the capability of our system in its present configuration. To achieve this specification, it will be necessary to either obtain an encoder with $0.01 \mu \mathrm{m}$ of resolution, or find a method for microstepping one of the inchworm motors.

\section{Computer Control System}

The PDCS is run by an IBM model AT personal computer utilizing software written in the ASYST 2.0 language. The devices used to operate the instrument are controlled by the computer through an IEEE-488 parallel interface, as shown in Fig. 4. Five devices are linked to the computer through the interface: two Compumotor 3000 indexers for the eight stepper motors, the Burleigh inchworm controller, an Ortec model 918A multi-channel buffer, and a CAMAC crate. The interface is operated in a synchronous (foreground only) mode.

The software responsible for the initialization of the instrumentation associated with the PDCS is contained within the MAINLOAD.UTL program. This program (1) defines the windows used for the display, (2) defines large memory arrays and variables, (3) allows access to the position memory, (4) defines GPIB addresses, (5) initializes the GPIB bus, (6) loads specialized programming for the operation of the PDCS instrumentation, and (7) initializes the PDCS instrumentation.

Since the stepper motors for the PDCS are operated open loop i.e., no devices such as encoders are used to obtain positional feedback, a system has been devised to keep track of the positions of the different axes as the PDCS is moved from position to position. The ASYST data file POS.MEM stores five integer values associated with the $2 \Theta \mathrm{A}, \Theta \mathrm{A}, \Theta \mathrm{B}$, $2 \Theta B$ course positioning mechanisms and the $2 \Theta \mathrm{A}$ fine motion. If any of the axes are moved, the operating program will retrieve the data values from POS.MEM. The data values will be changed according to the change in position of the axes, and the new position data will be restored in the POS.MEM file. The inchworm systems do not require this type of data storage, because they are operated closed loop. 


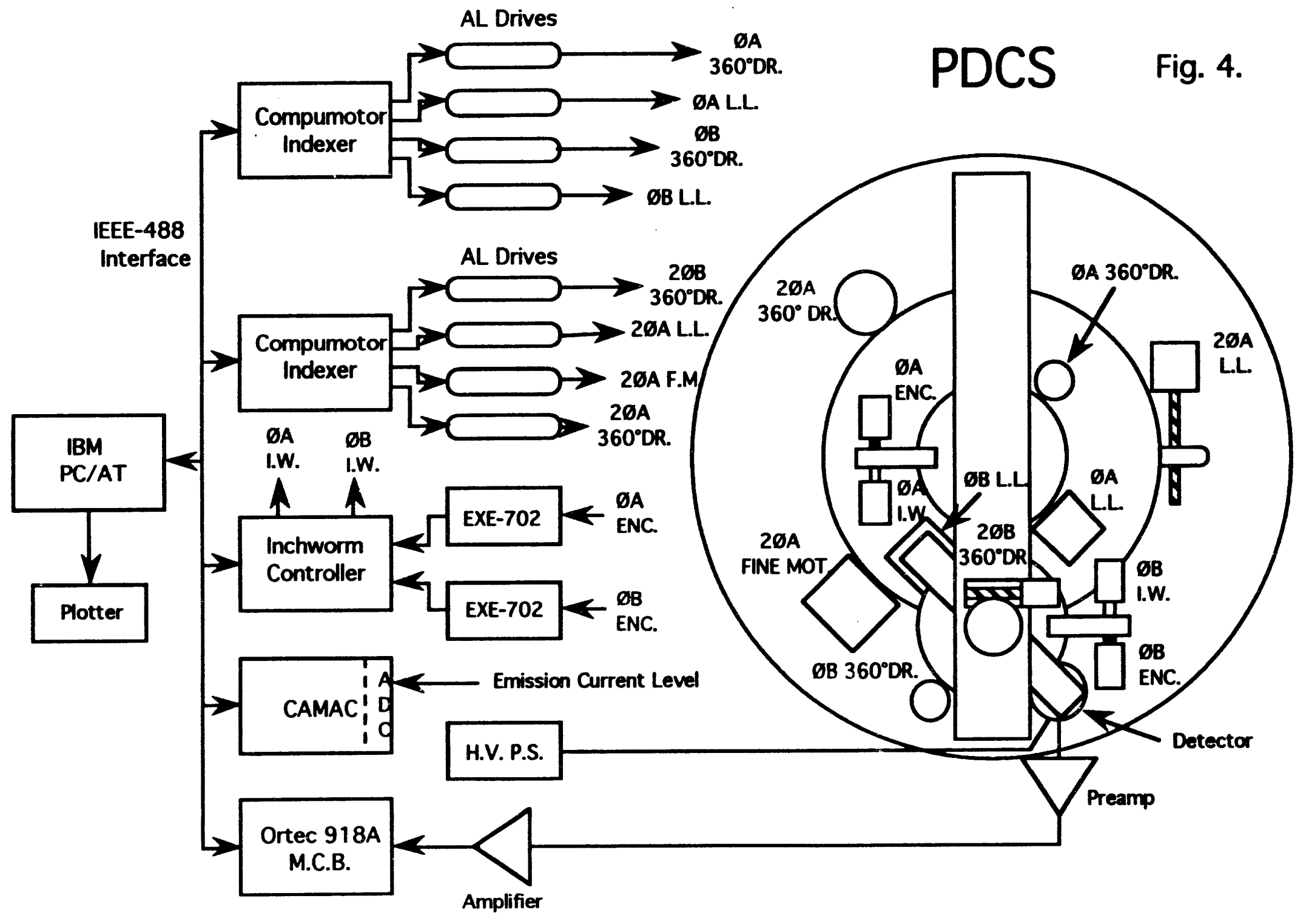


A program called ALIGNMENT.WRD is responsible for assigning an initial integer value to each of the five open loop positioning sub-systems. A HeNe laser is set up opposite the $\mathrm{x}$-ray source to simulate the $\mathrm{x}$-ray beam exiting the $\mathrm{x}$-ray tube. The yoke is then manually positioned parallel to the beam axis with the $\Theta B$ axis opposite the $x$-ray tube, with the inchworm system energized and engaged. The $\mathrm{OA}$ and $\mathrm{OB}$ crystals are positioned to reflect the laser beam off the back of the crystals, at a $180^{\circ}$ angle. The detector is aligned on the beam axis, "looking into" the x-ray tube. This is the "zero position" of the spectrometer, and the appropriate integer values are assigned to the position variables, and down-loaded into POS.MEM.

\section{Yacuum System}

The vacuum system for the PDCS is shown in Fig. 5. The vacuum chamber is initially at atmospheric pressure with both the gate valve and the throttle valve closed. The rotary vane pump is turned on, and the zeolite trap is outgassed by a resistance heater. Once the zeolite trap has been sufficiently outgassed, the throttle valve is opened, and evacuation of the vacuum chamber is begun. The pressure is monitored with a thermocouple gauge, and overnight, the pressure drops into the $10^{-3}$ torr range.

The turbo-pump is responsible for obtaining high vacuum for the PDCS. The turbo-pump is initially roughed out to approximately $10^{-2}$ torr by a mechanical fore-pump with the gate valve closed. The gate valve is operated by a cylinder of compressed air. The turbo-pump is then turned on, the gate valve is opened, and the throttle valve is closed. The rotary vane pump may then be taken off line, and returned to atmospheric pressure. The vacuum chamber ultimately reached a pressure of $2 \times 10^{-6}$ torr.

It is necessary to protect the pumping system components from a loss of power. The vacuum system is powered through the emergency power system in room 60 , but this power system has been unreliable in the past. A power sensor system has been incorporated which closes the gate valve on a loss of power. This power sensor system must be turned on by the operator, and the compressed air system valve line up must be in the proper position. A loss of power (for more than ten minutes) also causes a valve in the turbo-pump foreline to open, which initializes a slow leak. This leak is designed to slow the turbo-pump rotor, thereby preventing damage caused by the loss of the levitating magnetic field. A battery pack provides emergency power to the levitating magnetic field, if power is lost to the turbo-pump controller. 


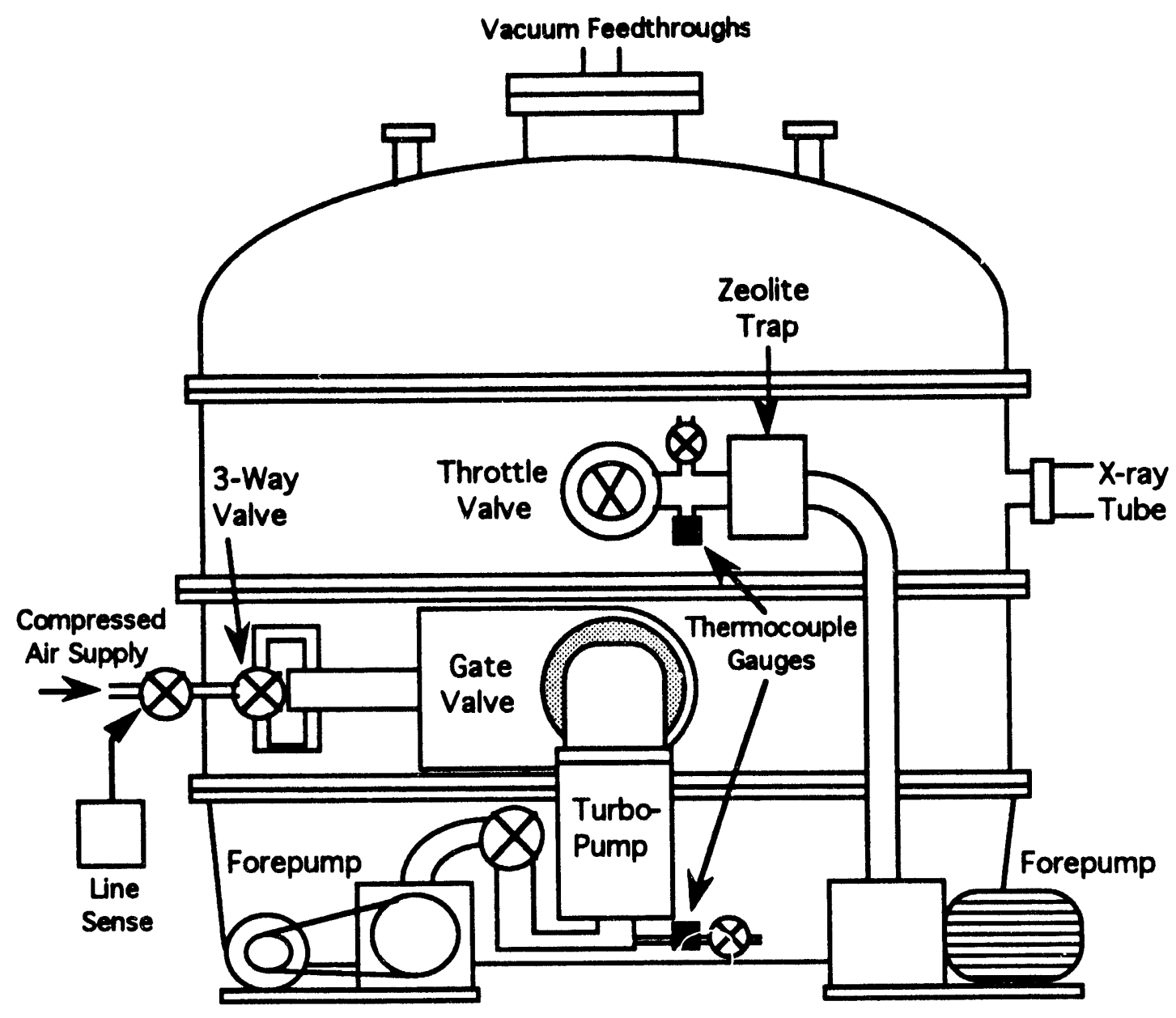

Fig. 5. PDCS Vacuum System. 


\section{OPERATING INSTRUCTIONS}

To operate the PDCS, the power to the NIM bin, CAMAC crate, Compumotor controllers, AL drives, inchworm controller, and the EXE electronics must all be turned on. The operator must enter the properly configured ASYST mode, and receive an "OK" prompt. The operator must type

\section{OK LOAD MAINLOAD.UTL}

and type a carriage return. This will load most of the special programming for the PDCS. After MAINLOAD.UTL has been loaded, the computer should respond with:

Hit F3 to initialize the system...

OK

The operator hits the F3 key, and the on-line equipment will report the status of the initialization back to the computer. If all the on-line equipment is properly initialized, the computer will automatically load the display menu programming, and respond with:

Hit F3 to display the main menu...

OK

The operator hits the F3 key, and the main menu is displayed. The main menu is shown in Fig. 6. This display shows the lift/lock status of the indexing tables, the position data for all the axes, and the list of available PDCS operations. The operator must now select the desired operational program.

\section{Alignment Program}

By selecting F9 on the main menu, the operator loads the alignment program. This program is presently designed to give an approximate alignment of the rotational positions of the axes using a He-Ne laser, when the PDCS is equipped with crystals whose front and back optical faces are parallel to the Bragg planes. The crystals, yoke, and detector are aligned according to the instructions given on the computer screen by the alignment program. Once the alignment has been achieved, the operator should hit the F10 key to store the zero-position data in POS.MEM. After this has been accomplished, the PDCS 


\begin{tabular}{|c|c|c|c|}
\hline AXIS & LETAOCK & COURSE POS.DAT & EINE POS.DAT \\
\hline 2.TH.A & LOCKED & $(+/-360) 0$ & $(0-9000) \quad 0$ \\
\hline TH.A & LOCKED & $(+/-360) \quad 0$ & $(0-9000) 0$ \\
\hline TH.B & LOCKED & $(+/-360) 0$ & $(0-9000) 0$ \\
\hline 2.TH.B & & & $(+/-36 \mathrm{E} 3) \quad 0$ \\
\hline OK & & & \\
\hline \multicolumn{4}{|c|}{ MAIN MENU } \\
\hline \multicolumn{2}{|c|}{ F4 Axis Positioning } & \multicolumn{2}{|c|}{ F5 Scan Sequence $(n, n)$} \\
\hline \multicolumn{2}{|c|}{ F6 Rocking Curve $(n,-n)$} & \\
\hline \multicolumn{2}{|c|}{ F8 Set Detector High Voltage } & \multicolumn{2}{|c|}{ F9 Align Instrument } \\
\hline
\end{tabular}

Fig. 6. Main Menu.

position may only be changed by using the scan programs which are designed to continuously update the position of the PDCS axes.

\section{Scan Programs}

Before starting a scan program, the detector system should be made ready. The gas valve for the flowing gas proportional counter should be opened, and the detector high voltage should be turned on. The power to the detector electronics should be turned on, and the $x$-ray tube should be energized by turning on the anode high voltage and the filament power supply. The operator should then select either the Scan Sequence $(n, n)$, or the Rocking Curve $(n,-n)$ operating program from the main menu by selecting the appropriate " $\mathrm{F}$ " key.

The Scan Sequence $(n, n)$ is the operating program used for obtaining dispersive $x$ ray spectra, and loaded when the operator selects the F5 key from the main menu. The program will prompt the operator for the initial and final Bragg angles of the scan. The operator must subdivide these Bragg angles into degrees (truncated to the nearest 0.25 degrees) and arc seconds (0-900 arc seconds). The operator must also choose the scan 
increment and the preset charge. The preset charge is simply the $\mathbf{x}$-ray tube emission current, which is monitored by an analog-to-digital converter in the CAMAC crate, integrated over time. The counting time interval is therefore determined by the $\mathrm{x}$-ray tube emission current and the value for preset charge entered by the operator. The PDCS will perform the scan automatically according to the input parameters. The data, which contains the number of $x$-ray counts as a function of the Bragg angle, is stored in a standard data file named SCAN.DAT. The operator must rename this data file to retain the data, because SCAN.DAT will be deleted the next time the program is run.

The operator may run the Rocking Curve $(n,-n)$ program by selecting the F6 key on the main menu. The operator selects the appropriate parameters when prompted to do so by the computer, in a manner similar to the Scan Sequence $(n, n)$ program. The PDCS will perform the rocking curve automatically, according to the input parameters, and store the data in ROCKING.DAT, which is a standard data file. The operator must rename this data file to save the data, because ROCKING.DAT will be deleted the next time the program is run. 


\section{OBSERVATIONS OF THE COPPER K $\alpha$ LINES}

\section{X-ray Tube}

The $\mathrm{x}$-ray source used to test the PDCS is shown in Fig. 7. X-rays are produced as electrons from the hot filament strike the anode. The $x$-rays leave the anode, travel through the thin aluminum window and the collimator, and are then observed by the PDCS. An ultra-high vacuum system maintains the $x$-ray tube at $10^{-8}$ torr.

The $x$-ray tube utilizes the combination of an ion pump and a titanium sublimation pump to maintain vacuum in the $x$-ray tube. Indium gaskets were used to make the necessary seals in the vacuum system. The system was initially roughed-out to approximately $1 \times 10^{-7}$ torr by an $80 \mathrm{l} / \mathrm{sec}$ diffusion pump backed by a mechanical forepump. After the system was roughed-out, a low-temperature $\left(-100^{\circ} \mathrm{C}\right)$ bakeout was performed. The ion pump and sublimation pump were turned on, and the vacuum system was isolated from the roughing pumps. The ultimate vacuum pressure achieved was $<1.0$ $x 10^{-9}$ torr, but the system typically ran at $\sim 10^{-8}$ torr with the $x$-ray tube turned on. These pressures were measured by an ionization gauge mounted on the $x$-ray tube.

A copper anode was used to generate a characteristic $x$-ray spectrum for observation by the PDCS. The copper anode was cooled by cooling fins. located outside the vacuum, and a fan. The electron beam was generated by thermionic emission from a got thoriacoated iridium filament. The electrons, incident on the copper anode, generated $x$-rays emitted in a direction perpendicular to the anode, thereby limiting anode self-absorption. The $\mathrm{x}$-rays emitted by the anode must travel through a thin aluminum window which serves as the vacuum boundary between the $\mathrm{x}$-ray tube and the PDCS.

\section{Copper $\mathrm{K} \alpha$ Spectrum and Rocking Curves}

The copper $K \alpha_{1}$ and $K \alpha_{2}$ lines obtained by the PDCS are shown in Fig. 8. The data was obtained by operating the scan program in first order. The $x$-ray tube was operated at $15 \mathrm{kV}$, with an emission current of approximately $3.0 \mathrm{~mA}$. The preset charge was set for $1.5 \mathrm{C}$, which corresponds to a counting time interval of about $500 \mathrm{sec}$. The scan was performed in increments of 4.5 arc seconds, from a Bragg angle of about $10.25^{\circ}$ to $10.35^{\circ}$.

The rocking curve obtained by the PDCS for the copper source is shown in Fig. 9. This rocking curve was taken at the Bragg angle corresponding to the $\mathrm{K} \boldsymbol{\alpha}_{1}$ line determined by the data shown in Fig. 8 . The $\mathrm{x}$-ray tube anode was held at $15 \mathrm{kV}$, with an emission 


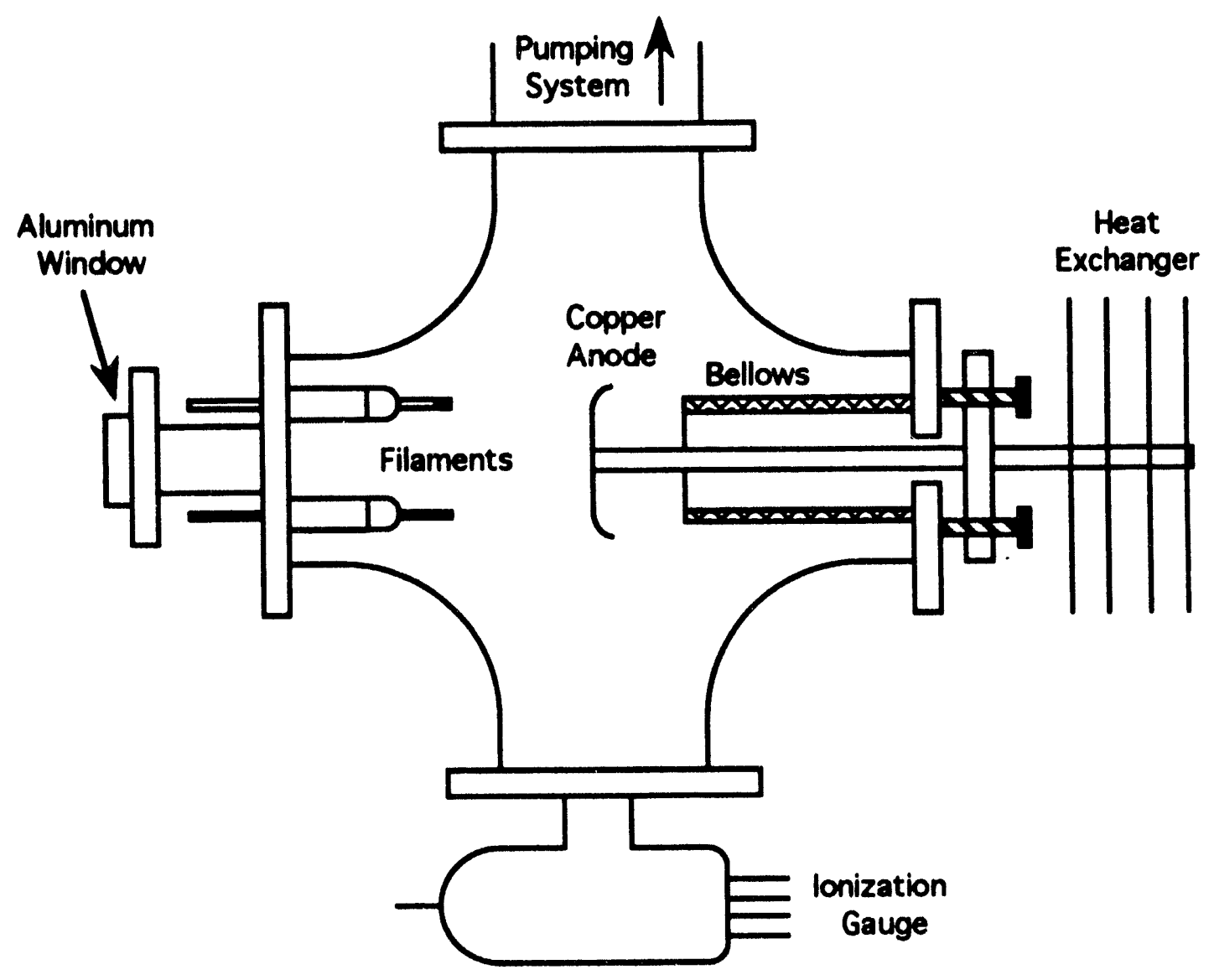

Fig. 7. X-ray Source.

current of approximately $2.0 \mathrm{~mA}$. The preset charge was $0.5 \mathrm{C}$, which corresponds to a counting time interval of about $25 \mathrm{sec}$. The rocking curve was performed in increments of 1.0 arc seconds over a range of approximately 30 arc seconds. 


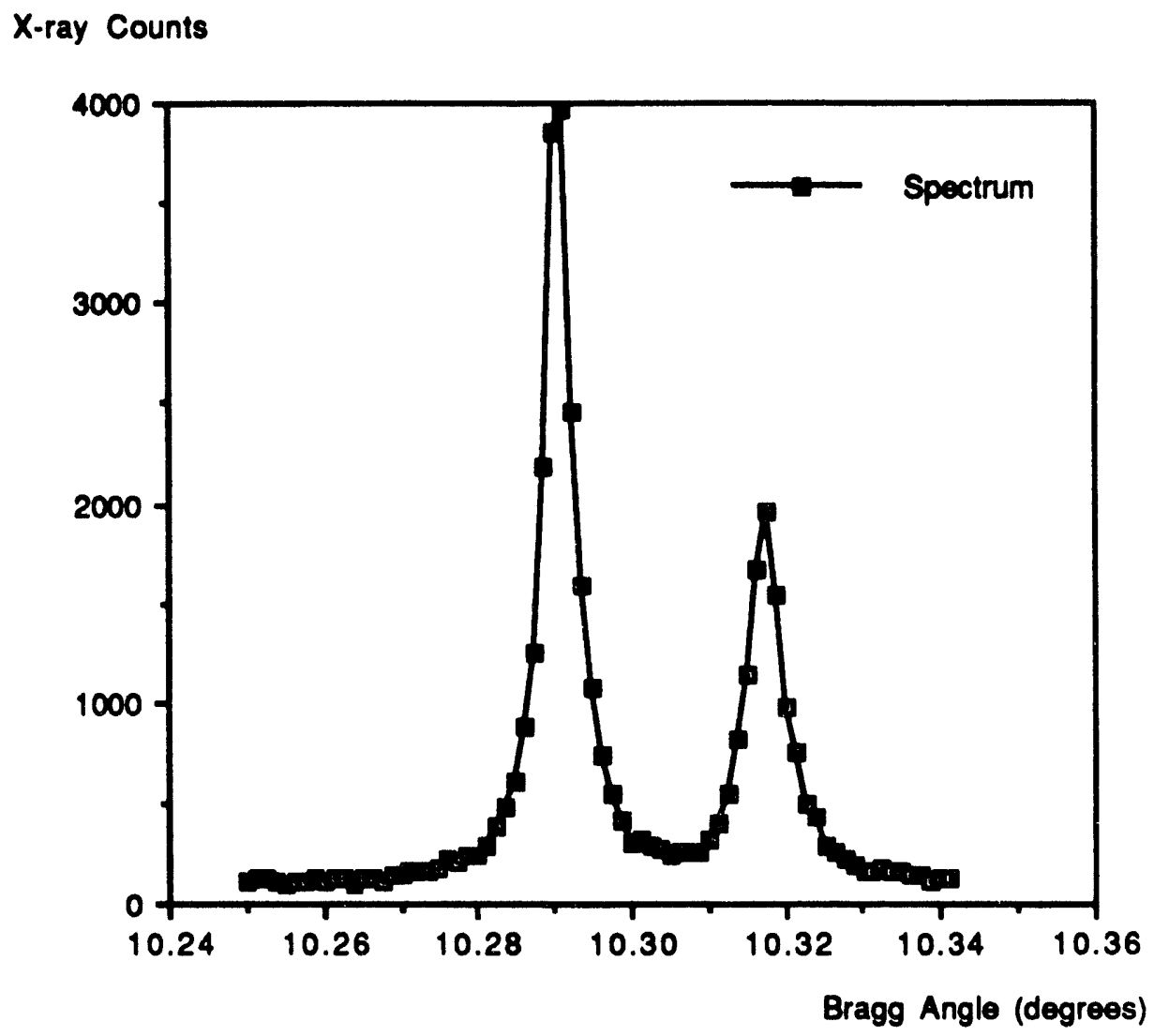

Fig. 8. Copper Ka X-ray Emission Spectrum. 


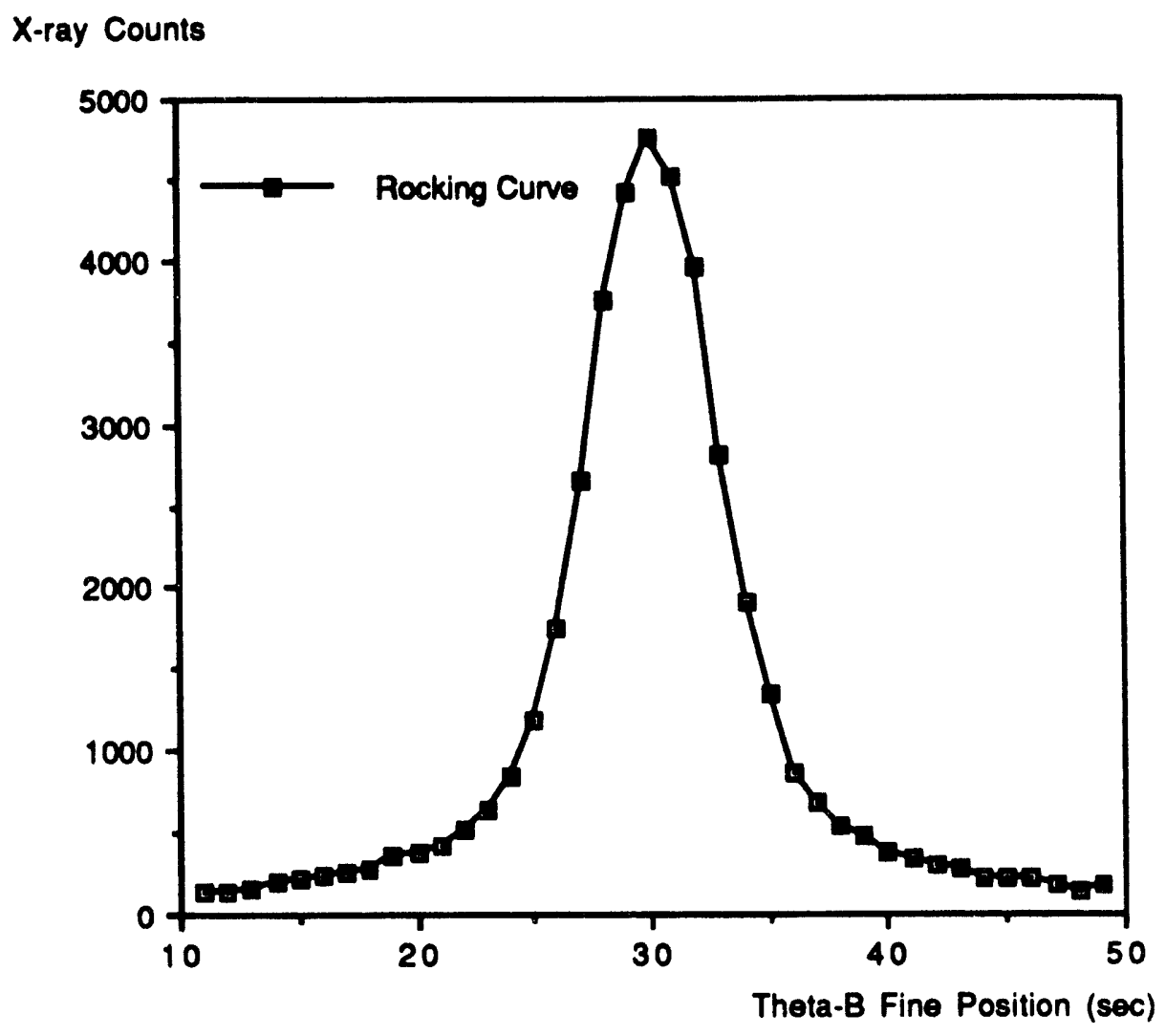

Fig. 9. Rocking Curve. 


\section{PDCS CHARACTERISTICS AND SPECIFICATIONS}

\section{Comparison of LANL. P-14 Specifications with Measured Specifications}

A comparison of LANL P-14 Specifications with the actual achieved characteristics of the PDCS is shown in Table 1. Some of the specifications described the P-14 statement of work for the MST contract have not been included in Table 1 for various reasons. The need for encoders for the stepping motors were included as an instrument specifications, and we have shown that these encoders are not necessary. Specifications were made for the fine scan range of motion to be $1.0^{\circ}$ for $\mathrm{OA}$ and $\mathrm{OB}$, and $2.0^{\circ}$ for $28 \mathrm{~A}$ and $28 \mathrm{~B}$, but in fact the fine scan range is $360^{\circ}$ for all axes. The temperature stability and control specification of $\pm 0.1^{\circ} \mathrm{C}$ has not yet been tested.

Table 1.

PDCS Characteristics and Specifications.

\begin{tabular}{|c|c|c|c|}
\hline & Specification & Achieved Value & Measurement Method \\
\hline Vacuum & $1 \times 10^{-7}$ tor & $2 \times 10^{-6}$ tor & Ionization Gauge \\
\hline Scan Range & $0^{\circ}$ to $\pm 80^{\circ}$ & $0^{\circ}$ to $\pm 80^{\circ}$ & Visual Observation \\
\hline $\begin{array}{c}\text { Angular Precision, } \\
\text { OA, OB, 2OA }\end{array}$ & $0.1 \operatorname{arc~sec}$ & ................ & -.............. \\
\hline $\begin{array}{c}\text { Angular Resolution, } \\
\mathrm{OA}, \boldsymbol{\Theta B}, 2 \Theta \mathrm{A}\end{array}$ & 0.01 arc sec & 0.1 arc sec & $\begin{array}{l}\text { Heidenhain Inch- } \\
\text { worm Encoder }\end{array}$ \\
\hline $\begin{array}{c}\text { Parallelism, } \\
\boldsymbol{\Theta A}, \boldsymbol{\Theta B}, 2 \boldsymbol{A} \mathrm{A}\end{array}$ & $10 \operatorname{arcsec}$ & $10 \operatorname{arcsec}$ & Auto-collimator \\
\hline $\begin{array}{l}\text { Coaxiality, } \\
\text { QA, 2OA }\end{array}$ & $0.5 \mu \mathrm{m}$ & $7 \mu \mathrm{m}$ & Cross-hair Width \\
\hline $\begin{array}{c}\text { Angular Resolution, } \\
2 \Theta B\end{array}$ & $10 \operatorname{arcsec}$ & 18 arc sec & Auto-collimator \\
\hline
\end{tabular}

The ultimate vacuum pressure obtained by our pumping system was $2 \times 10^{-6}$ torr as measured by an ionization gauge, while the specifications called for a vacuum pressure of $1.0 \times 10^{-7}$ torr. A vacuum pressure of $2 \times 10^{-6}$ :orr allows for a sufficiently long mean free path for ultra-soft $x$-rays, and is also low enough to prevent damage to the inchworm motors and stepper motors in the plasma breakdown region of $1 \times 10^{-4}$ to 100 torr. These 
motors should never be operated in this pressure range. The only reason for operating the PDCS at $1 \times 10^{-7}$ torr is to use a windowless photo-electric detector for the observation of ultra-soft $x$-rays. If this type of experiment is to be performed, it may be necessary to improve the vacuum chamber pressure. This may be accomplished by the implementation of a high vacuum pump with a pumping speed that is an order of magnitude faster.

The achieved value for angular accuracy has been omitted from Table 1. Our method for determining this value was to use an auto-collimator mounted on a separated MST precision 1440 indexing table, to observe the reflection from an optical flat mounted on the axis under test. The reference table and the associated axis were counter-rotated by $0.25^{\circ}$, and displacement of the auto-collimator image would have been observed if it were present. This calibration system is limited by the visual acuity of the auto-collimator observer, and we estimate this uncertainty to be slightly greater than 1.0 arc seconds. The random counter-rotation checks showed no visible displacement of the auto-collimator image, but all 1440 positions of the $\Theta A$ and $\Theta B$ indexing tables, and all 720 positions of the $28 \mathrm{~A}$ indexing table have yet to be checked.

\section{Euture Work}

Having achieved the goal of making the PDCS a functioning instrument, we must now focus on achieving the design specifications. Since the d-spacing of the crystals is dependent on the temperature of the crystals, accurate temperature measurements of the crystals must be made. No attempts have yet been made to determine if the $0.1^{\circ} \mathrm{C}$ temperature stability and control specification can be achieved. Another problem which needs to be addressed is the specification for an absolute angular accuracy of 0.1 arc seconds for the $\mathrm{QA}, \boldsymbol{\Theta B}$ and $2 \mathrm{QA}$ axis positions. The observations of these small angles vill only be possible with an improved auto-collimator system.

For the PDCS to perform precision measurements of crystal d-spacings and $x$-ray wavelengths, two additional programs must be added to the list of PDCS operational programs. The PDCS is capable of operating as a single crystal instrument for $x$-ray reflections from both the $\Theta A$ and $\Theta B$ crystals. Using rotatable crystal holders, the angle of the Bragg reflecting planes compared to the optical face of the crystal could be determined, and the crystals could be positioned until the Bragg planes are parallel to the crystal axes of rotation.

The second computer program which needs to be developed is a four-theta-Bragg $\left(4 \Theta_{B}\right)$ program, which takes advantage of the symmetry of the PDCS. The scan sequence $(n, n)$ program can also be run in a position $(-n,-n)$ that is a mirror image with respect to the 
input $x$-ray beam. The position difference for the $\Theta A$ and $\Theta B$ axes for the spectral peak in the $(n, n)$ position compared to the $(-n,-n)$ position is $180^{\circ}-2 O_{B}$, while the difference in the $28 \mathrm{~A}$ position will be $4 \theta_{\mathrm{B}}$ (which gives the operating program its name). By comparing the $(n, n)$ data with the $(-n,-n)$ data, the Bragg angle of the spectral peaks can be determined with a high degree of accuracy. 


\section{APPENDIX A \\ PDCS PROGRAMMING}

\section{MANILOAD.UTL}

\section{ECHO.OFF}

IMAINLOAD.UTL is a command file for setting up a utilites menu and loading

Ithe various utility programs.

IThe following instrument control subprograms are required:

I 918.WRD.............Provides for control of the Ortec 918A MCB

I MOTOR.WRD............Provides for control of the Compumotor Indexers

I IW.WRD..............Provides for control of the Inchworms

1 MAINTCAM.WRD........Provides for control of the CAMAC Crate

। READ.FIL.............Converts BASIC data files to ASYST variables

\The following spectrometer operational subprograms are required:

I MENU.WRD............Loads the menu \& display

I ONE-XTAL.WRD........ Operates the Spectrometer in Single-Crystal Mode

I SCAN.WRD............. Operates the Spectrometer in $(n, n)$ Scan Mode

I SCAN2.WRD............ Operates the Spectrometer for $(n,-n)$ Rocking Curves

I AXIS-POS.WRD.........Allows independent axis positioning \& position memory

I ALIGNMENT.WRD.......Sets the zero DCS position into position memory

\section{\ DEFINE WINDOWS}

00179 WINDOW (SCALE)

2059 WINDOW (AXES)

210222 WINDOW (LIFT/LOCK.2.TH.A)

310322 WINDOW (LIFT/LOCK.TH.A)

410422 WINDOW [LIFT/LOCK.TH.B]

223533 WINDOW [CPDI]

234242 WINDOW (CPD.2.TH.A)

334342 WINDOW [CPD.TH.A]

434442 WINDOW (CPD.TH.B)

243553 WINDOW (FPD1)

254264 WINDOW (FPD.2.TH.A)

354364 WINDOW [FPD.IW.A]

454464 WINDOW (FPD.IW.B)

554564 WINDOW (FPD.2.TH.B)

265579 WINDOW [BRAGG]

1902479 WINDOW (MAIN.BOT)

22322240 WINDOW (BRAGG0)

23322340 WINDOW (BRAGGF)

24302440 WINDOW [SCAN.INC)

001879 WINDOW (MAIN.TOP)

601879 WINDOW (MAIN.MID)

\ DEFINE LARGE MEMORY VARIABLES 
1000 STRING "MOTOR.DATA

20 STRING "918.STAT

20 STRING "918.SSTAT

100 STRING "IW.DATA

REAL DIM[ 2000 ] ARRAY XX

REAL DIM[2000] ARRAY YY

INTEGER DIM[ 7] ARRAY POS.DAT

\ DEFINE POSITION MEMORY

: POS.DAT >MEM

FLE.OPEN POS.MEM

1 SUBFILE POS.DAT ARRA Y $>$ FILE

FILE.CLOSE

;

\section{: POS.MEM $>$ DAT}

FILE.OPEN POS.MEM

1 SUBFILE POS.DAT FILE $>$ ARRAY

FILE.CLOSE

;

\ DEFINE GPIB.ADDRESSES

1 GPIB.DEVICE MOTOR 1

2 GPIB.DEVICE MOTOR2

3 GPIB.DEVICE 972AMP

4 GPIB.DEVICE CRATE1

5 GPIB.DEVICE 918MCB

6 GPIB.DEVICE 974AMP

7 GPIB.DEVICE IW

। PROGRAM TO INITIALIZE GPIB BUS

: GPIB.INIT

BUS.INIT

SEND.INTERFACE.CLEAR

REMOTE.ENABLE.ON

IINITLALIZE THE BUS

: INIT.OK

STACK.CLEAR

LOAD MENU.WRD

ECHO.ON

;

LOAD C:MAINTCAM.WRD

LOAD C:918.WRD

LOAD C:IW.WRD

LOAD C:MOTOR.WRD

LOAD C:READ.FIL

: DO.INIT 


\section{NORMAL.DISPLAY \\ GPIB.INIT \\ MOTOR1.INIT \\ MOTOR2.INIT \\ 918.INTT \\ CAMAC.INIT \\ IW.INIT \\ INIT.OK \\ ; \\ STACK.CLEAR}

F3 FUNCTION.KEY.DOES DO.INIT

NORMAL.DISPLAY

CR ." Hit F3 to initilize the system."

ECHO.ON

\section{WRD}

IPROGRAM TO WRITE COMMANDS TO THE ORTEC 918 MULTI-CHANNEL

BUFFER,

$\backslash$ THEN READ THE STATUS

ICOMMAND MUST BE IN THE SYMBOL STACK

IMAINLOAD.UTL MUST BE RUN FIRST

20 STRING "918.STAT

20 STRING "918.\$STAT

DP.REAL SCALAR COUNTS

REAL SCALAR N

REAL SCALAR M

INTEGER SCALAR PRESET

:ORTEC.CHK

"\%" "918.STAT "WITHIN ITEST FOR STATUS WORD (\%)

IF $1+3$ "918.STAT "SUB "DUP \SAVE FIRST 3 CHAR

" 000 " "WITHIN $\quad 1000=$ SUCCESS

IF ." OPERATION SUCCESSFUL." CR

ELSE " 001" "WITHIN 1001 = POWER UP

IF ." POWER-UP," "918.STAT GPIB.READ

" \%000" "918.STAT "WITHIN IF." OPERATION SUCCESSFUL." CR THEN ELSE ." ERROR " "918.STAT "TYPE CR THEN THEN

ELSE ." OUT OF SYNC" CR " ORTEC.PRT.DATA" "EXEC THEN

;

: ORTEC.PRT.DATA

" \$A" "918.SSTAT "WITHIN

IF $2+3$ "918.\$STAT "SUB

ITEST FOR DATA RECORD

"TYPE CR

ELSE " \$C" "918.\$STAT "WITHIN ITEST FOR C DATA RECORD 
IF $2+5$ "918.\$STAT "SUB IIF \$C, SAVE 5 CHAR

"TYPE CR

ELSE " SF" "918.\$STAT "WTTHIN ITEST FOR F DATA RECORD

IF $2+3$ "918.\$STAT "SUB IIF SF, SAVE 3 CHAR

"TYPE CR

ELSE " \$G" "918.\$STAT "WITHIN ITEST FOR G DATA RECORD

IF $2+10$ "918.\$STAT "SUB IIF \$G, SAVE 10 CHAR

"TYPE CR

ELSE " \$D" "918.\$STAT "WITHIN ITEST FOR D DATA RECORD

IF $2+10$ "918.\$STAT "SUB IIF \$D, SAVE 10 CHAR

"TYPE CR

ELSE " \$H" "918.\$STAT "WITHIN ITEST FOR H DATA RECORD

IF $2+8$ "918.\$STAT "SUB \IF \$H, SAVE 8 CHAR

"TYPE CR

ELSE ." NO \$A,\$C,\$D,\$F,\$G OR \$H RECORD " CR

THEN

THEN

THEN

THEN

THEN

THEN

"918.STAT GPIB.READ

ORTEC.CHK

;

IPROGRAM TO SEND COMMANDS TO 918 MCB

: ORTEC.COM
918MCB
GPIB.WRITE I WRITE TO 918
50 MSEC.DELAY I
"918.STAT GPIB.READ IREAD REPLY
ORTEC.CHK
;

IPROGRAM TO SHOW REQUESTED VALUES - COMMAND ON THE SYMBOL STACK

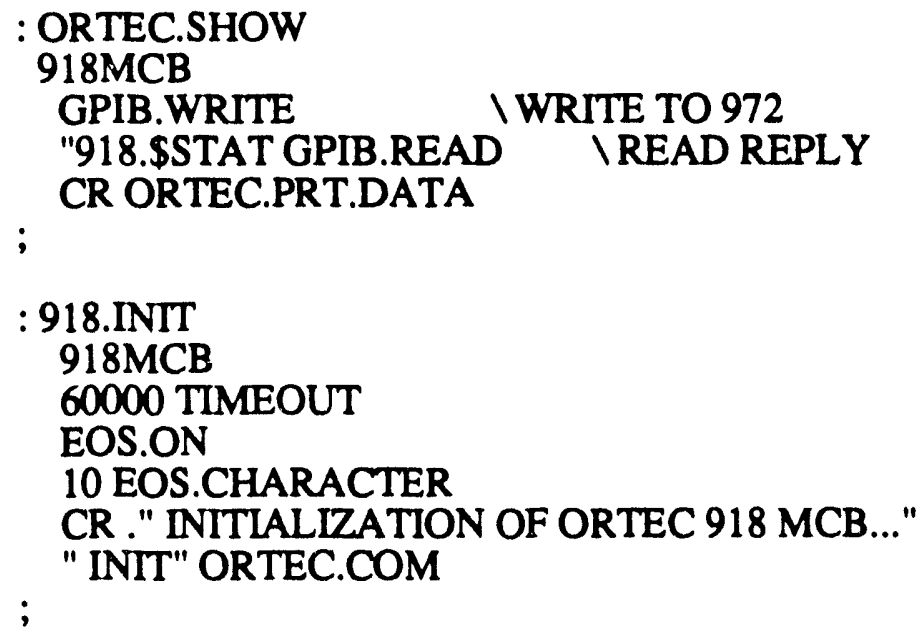




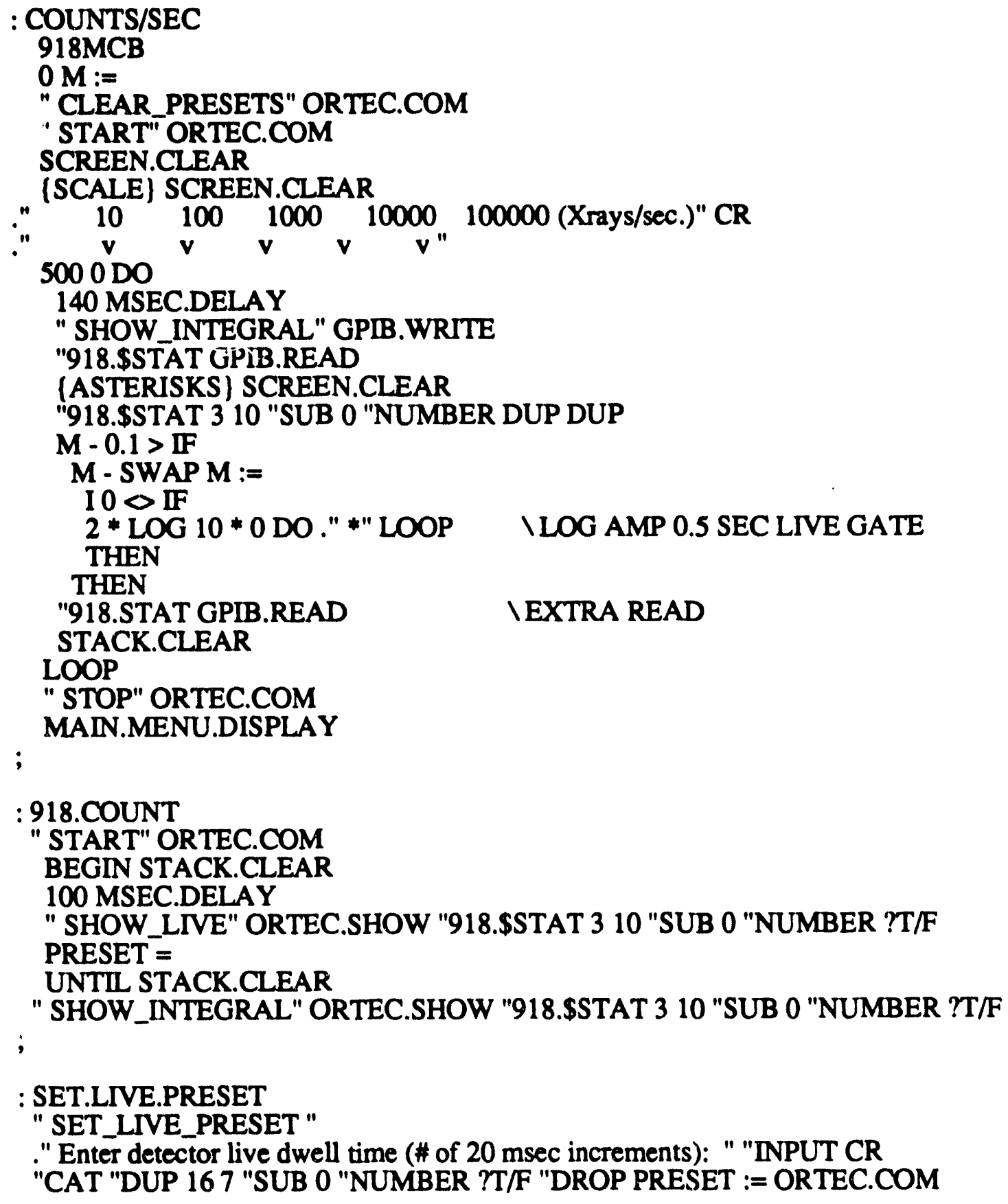

" Enter detector live dwell time (\# of $20 \mathrm{msec}$ increments): " "INPUT CR

"CAT "DUP 167 "SUB 0 "NUMBER ?T/F "DROP PRESET := ORTEC.COM

\section{MOTOR.WRD}

IPROGRAMS FOR THE TWO COMPUMOTOR 3000 INDEXERS

$\backslash 1000$ S'RRING "MOTOR.DATA (MAINLOAD.UTL)

INTEGER SCALAR STEP

:SPOLL 


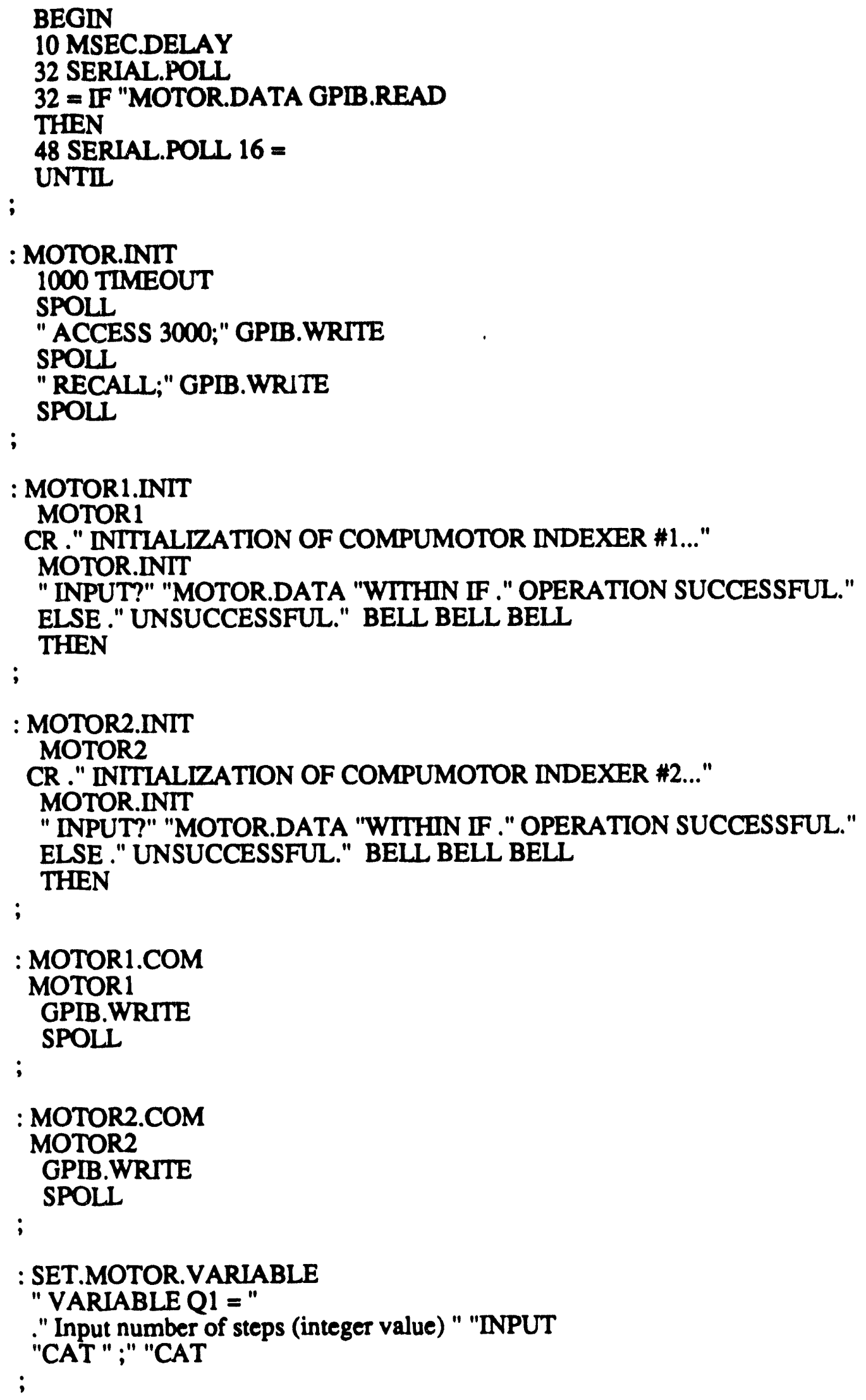




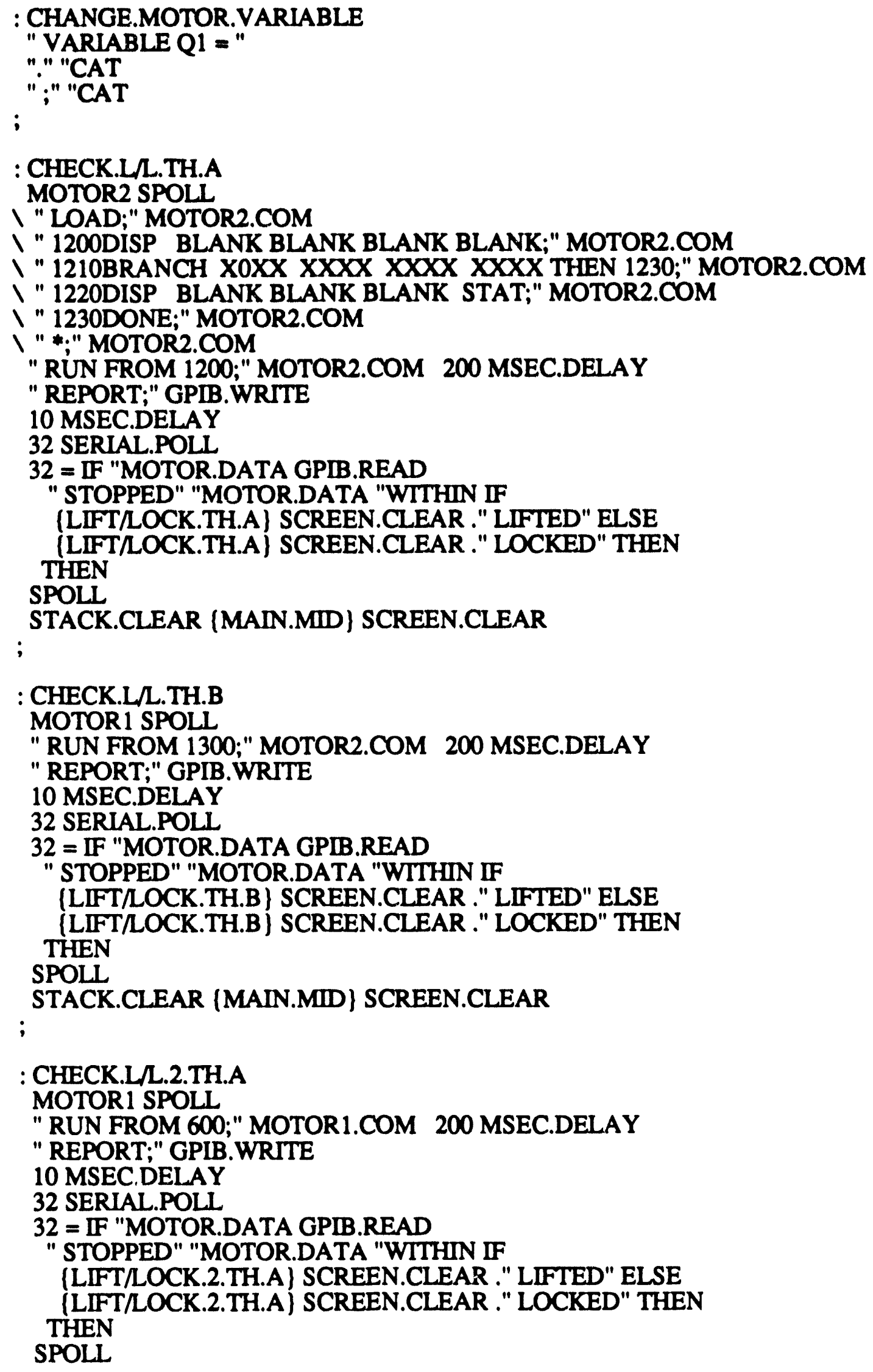


STACK.CLEAR (MAIN.MID) SCREEN.CLEAR ;

: CHECK.LR 100 MSEC.DELAY

CHECK.L/L.2.TH.A 100 MSEC.DELAY

CHECK.L $/$.TH.A 100 MSEC.DELAY

CHECK.L $\Omega$.TH.B 100 MSEC.DELAY

;

: 2.TH.A.SHTDN

" LOAD;" MOTOR1.COM

" 0950SHTDN NULL YES NULL NULL;" MOTOR1.COM

" 0960DONE;" MOTOR1.COM

" *;" MOTOR1.COM

" RUN FROM 950;" MOTOR1.COM

;

: 2.TH.A.LOCK

" LOAD;" MOTOR1.COM

" 0300BRANCH XOXX XXXX XXXX XXXX THEN 0380;" MOTOR1.COM

" 0310DISP BLANK BLANK STAT BLANK;" MOTOR1.COM

" 0320SHTDN NULL NULL NO NULL;" MOTOR1.COM

" 0330VELC $00000000500000000 ; "$ MOTOR1.COM

" 0340ACEL $0000000050000000 ; "$ MOTOR1.COM

" 0350MOVE 00000000-1388888 0000;" MOTOR1.COM

" 0360SHTDN NULL NULL YES NULL;" MOTOR1.COM

" O380DONE;" MOTOR1.COM

" *;" MOTOR1.COM

" RUN FROM 300;" MOTOR1.COM

$500 \mathrm{DO}$

(LIFT/LOCK.2.TH.A) SCREEN.CLEAR 400 MSEC.DELAY

" LOCKING" 400 MSEC.DELAY

LOOP

20 MSEC.DELAY CHECK.L/L.2.TH.A

20 MSEC.DELAY 2.TH.A.SHTDN

;

: 2.TH.A.STARTUP

" LOAD;" MOTOR1.COM

" 0900SHTDN NULL NO NULL NULL;" MOTOR1.COM

" O910DONE;" MOTOR1.COM

" *;" MOTOR1.COM

" RUN FROM 900;" MOTOR1.COM ;

: 2.TH.A.LIFT

2.TH.A.STARTUP 200 MSEC.DELAY

" LOAD;" MOTORI.COM

" 0400BRANCH X1XX XXXX XXXX XXXX THEN 0480;" MOTOR1.COM

" 0410DISP BLANK BLANK STAT BLANK;" MOTOR1.COM

" 0420SHTDN NULL NULL NO NULL;" MOTOR1.COM

" 0430VELC 00000000 50000 0000;" MOTOR1.COM

" 0440ACEL 000000005000 0000;" MOTOR1.COM

" 0450MOVE $0000000013888880000 ; "$ MOTOR1.COM 
" 0460SHTDN NULL NULL YES NULL;" MOTOR1.COM

" O480DONE;" MOTOR1.COM

" *;" MOTOR1.COM

" RUN FROM 400;" MOTOR1.COM

$500 \mathrm{DO}$

(LIFT/LOCK.2.TH.A) SCREEN.CLEAR 400 MSEC.DELAY

" LIFTING" 400 MSEC.DELAY

LOOP

20 MSEC.DELAY CHECK.L/L.2.TH.A

;

: TH.A.LIFT

" LOAD;" MOTOR2.COM

" 0500BRANCH X1XX XXXX XXXX XXXX THEN 560;" MOTOR2.COM

" 0510DISP BLANK BLANK BLANK STAT;" MOTOR2.COM

" 0520SHTDN NULL NULL NULL NO;" MOTOR2.COM

" 0530VELC 000000000000 10000;" MOTOR2.COM

" 0540ACEL 000000000000 5000;" MOTOR2.COM

" 0550MOVE 00000000 0000-50000;" MOTOR2.COM

" 0560SHTDN NULL NULL NULL YES;" MOTOR2.COM

" 0570DONE;" MOTOR2.COM

" *;" MOTOR2.COM

" RUN FROM 500;" MOTOR2.COM

$100 \mathrm{DO}$

(LIFT/LOCK.TH.A) SCREEN.CLEAR 400 MSEC.DELAY

(LIFT/LOCK.TH.A) ." LIFTING" 400 MSEC.DELAY

LOOP

20 MSEC.DELAY CHECK.L/L.TH.A

;

: TH.B.LIFT

" LOAD;" MOTOR2.COM

" 0800BRANCH XX1X XXXX XXXX XXXX THEN 860;" MOTOR2.COM

" 0810DISP BLANK STAT BLANK BLANK;" MOTOR2.COM

" 0820SHTDN NULL NO NULL NULL;" MOTOR2.COM

" 0830VELC $00001000000000000 ; "$ MOTOR2.COM

" 0840ACEL 000050000000 0000;" MOTOR2.COM

" 0850MOVE 0000 -500000000 0000;" MOTOR2.COM

" 0860SHTDN NULL YES NULL NULL;" MOTOR2.COM

" 0870DONE;" MOTOR2.COM

" *;" MOTOR2.COM

" RUN FROM 800;" MOTOR2.COM

$100 \mathrm{DO}$

(LIFT/LOCK.TH.B) SCREEN.CLEAR 400 MSEC.DELAY

. LIFTING" 400 MSEC.DELAY

LOOP

20 MSEC.DELAY CHECK.L/L.TH.B

;

: TH.A.LOCK

" LOAD;" MOTOR2.COM

" 0700BRANCH X0XX XXXX XXXX XXXX THEN 770;" MOTOR2.COM

" 0710DISP BLANK BLANK BLANK STAT;" MOTOR2.COM

" 0720SHTDN NULL NULL NULL NO;" MOTOR2.COM 
" 0730VELC 000000000000 10000;" MOTOR2.COM

" 0740ACEL 0000 00000000 5000;" MOTOR2.COM

" 0750MOVE 000000000000 50000;" MOTOR2.COM

" 0760SHTDN NULL NULL NULL YES;" MOTOR2.COM

" O770DONE;" MOTOR2.COM

" *;" MOTOR2.COM

" RUNN FROM 700;" MOTOR2.COM

$100 \mathrm{DO}$

\{LIFT/LOCK.TH.A\} SCREEN.CLEAR 400 MSEC.DELAY

" LOCKING" 400 MSEC.DELAY

LOOP

20 MSEC.DELAY CHECK.LR.TH.A

;

: TH.B.LOCK

"LOAD;" MOTOR2.COM

" 0900BRANCH XXOX XXXX XXXX XXXX THEN 970;" MOTOR2.COM

" 0910DISP BLANK STAT BLANK BLANK;" MOTOR2.COM

" 0920SHTDN NULL NO NULL NULL;" MOTOR2.COM

" 0930VELC 0000100000000 0000;" MOTOR2.COM

" 0940ACEL 0000 50000000 0000;" MOTOR2.COM

" 0950MOVE 0000 50000 0000 0000;" MOTOR2.COM

" 0960SHTDN NULL YES NULL NULL;" MOTOR2.COM

" O970DONE;" MOTOR2.COM

" *;" MOTOR2.COM

" RUN FROM 900;" MOTOR2.COM

$100 \mathrm{DO}$

[LIFT/LOCK.TH.B ] SCREEN.CLEAR 400 MSEC.DELAY

" LOCKING" 400 MSEC.DELAY

LOOP

20 MSEC.DELAY CHECK.L/.TH.B

;

: 2.TH.A.MOVE

"LOAD;" MOTOR1.COM

" 0500SHTDN NULL NO NULL NULL;" MOTOR1.COM

" 0510DISP BLANK STAT BLANK BLANK;" MOTOR1.COM

" 0520VELC 000015000000 0000;" MOTOR1.COM

" 0530ACEL 0000 1000 0000 0000;" MOTOR1.COM

" 0540MATH Q2 = Q1 * 1000;" MOTOR1.COM

" 0550MOVE 0000 Q2 0000 0000;" MOTOR1.COM

" 0560SHTDN NULL NULL NULL NULL;" MOTOR1.COM

" 0570DONE;" MOTOR1.COM

" *;" MOTOR1.COM

" RUN FROM 500;" MOTOR1.COM

$$
\text { ; }
$$

: 2.TH.A.ROTATE

MOTOR1 SPOLL

SET.MOTOR.VARIABLE MOTOR1.COM

2.TH.A.MOVE

;

: CHANGE.2.TH.A 


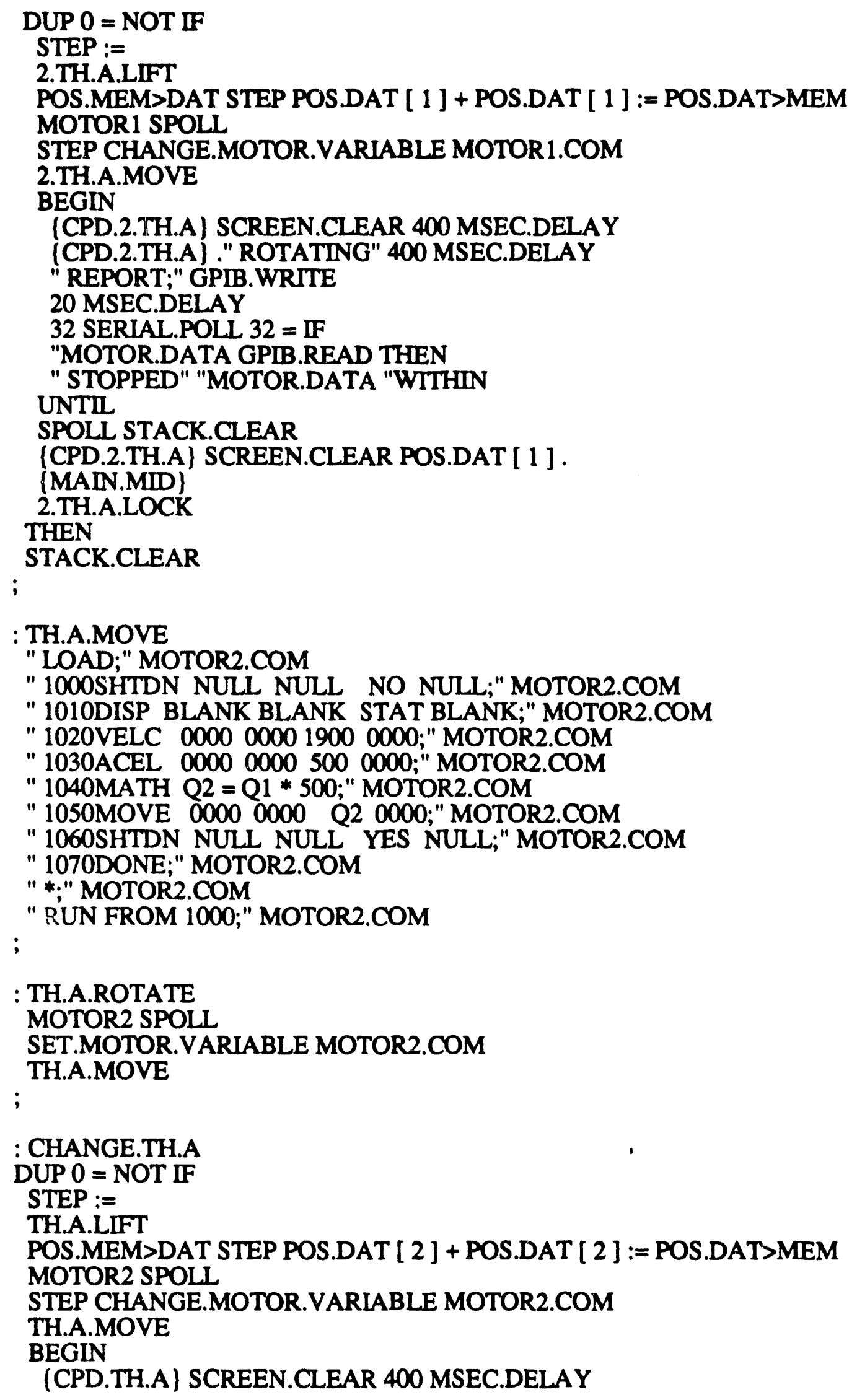




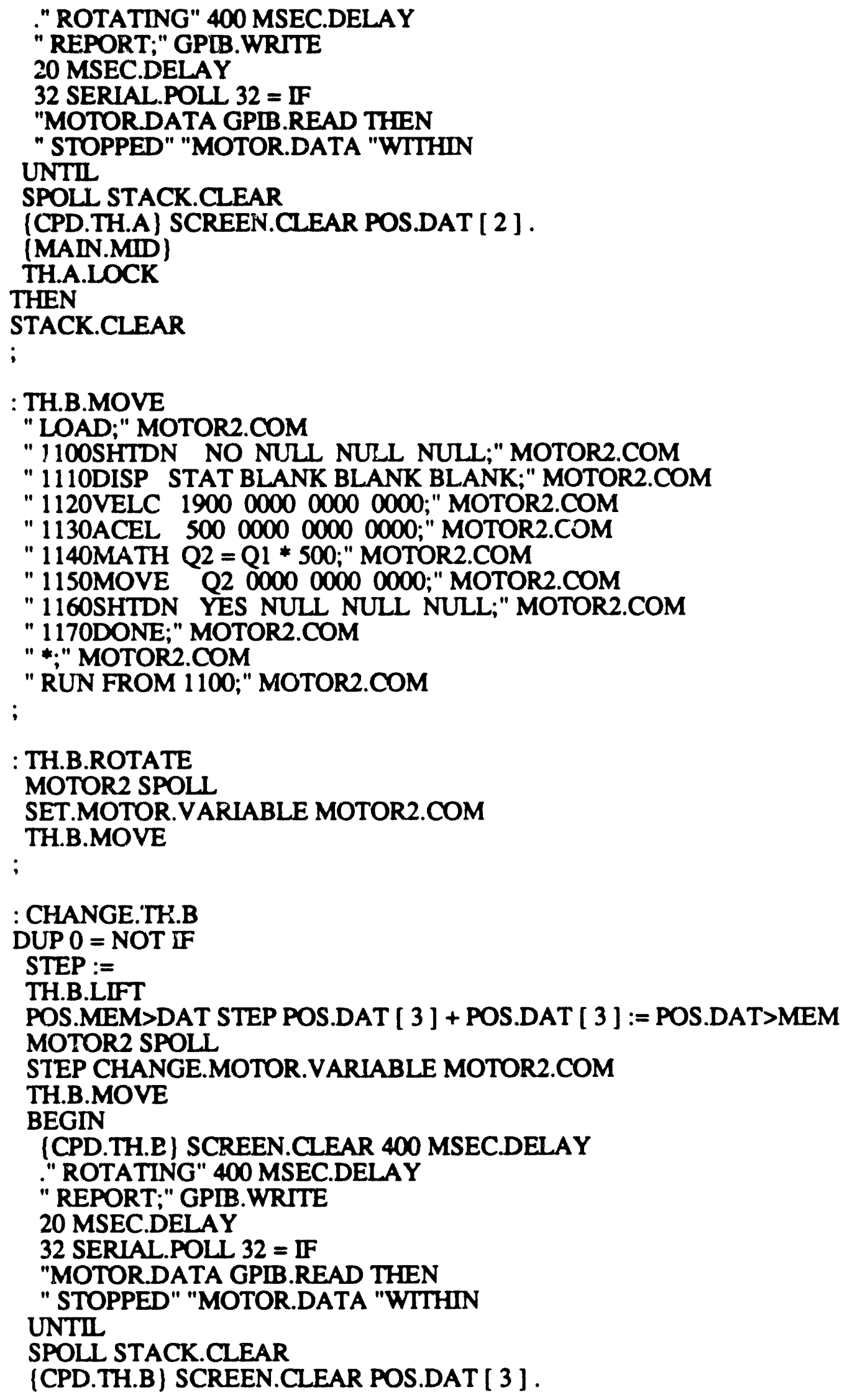

: TH.B.ROTATE MOTOR2 SPOLL SET.MOTOR.VARIABLE MOTOR2.COM 


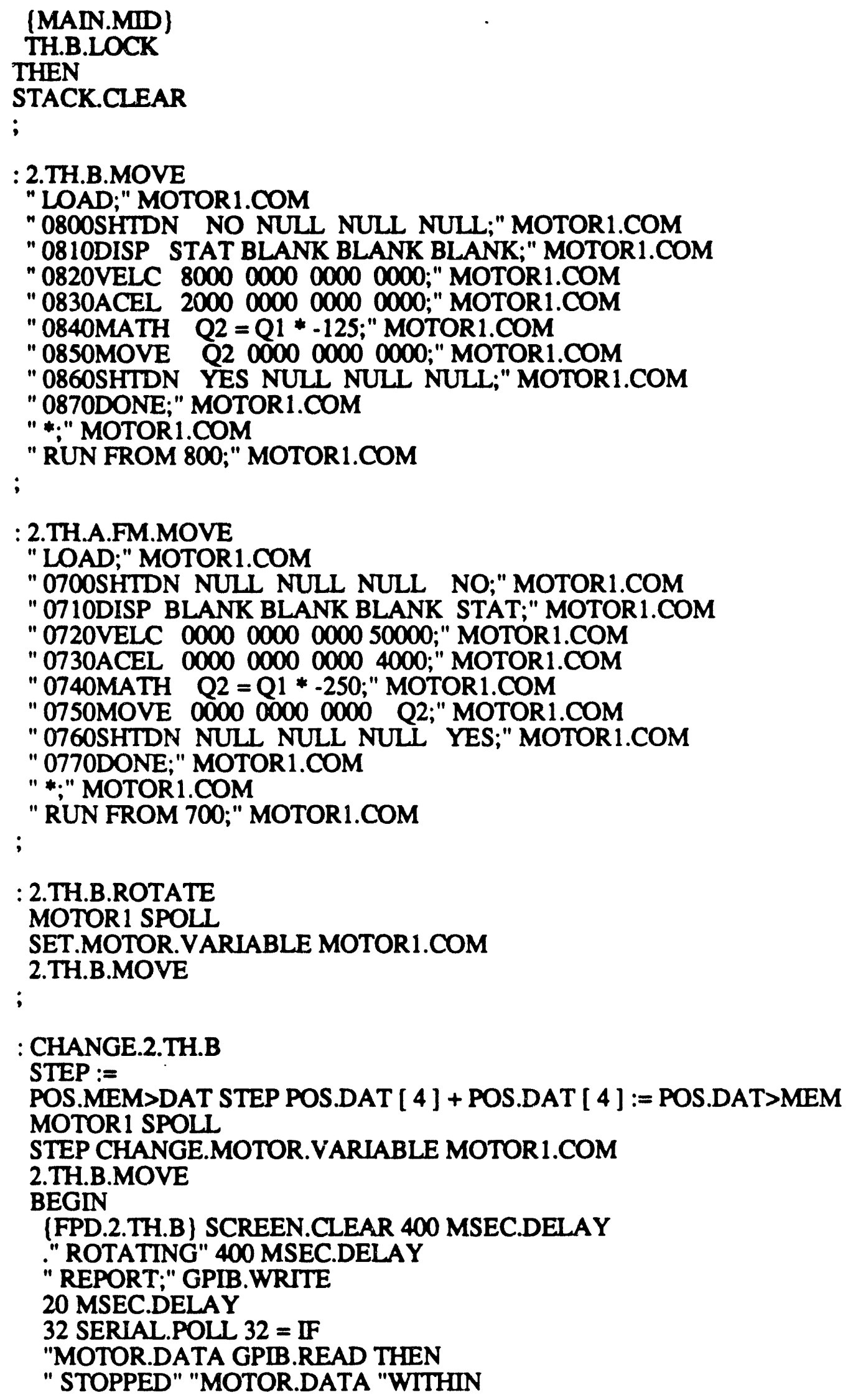




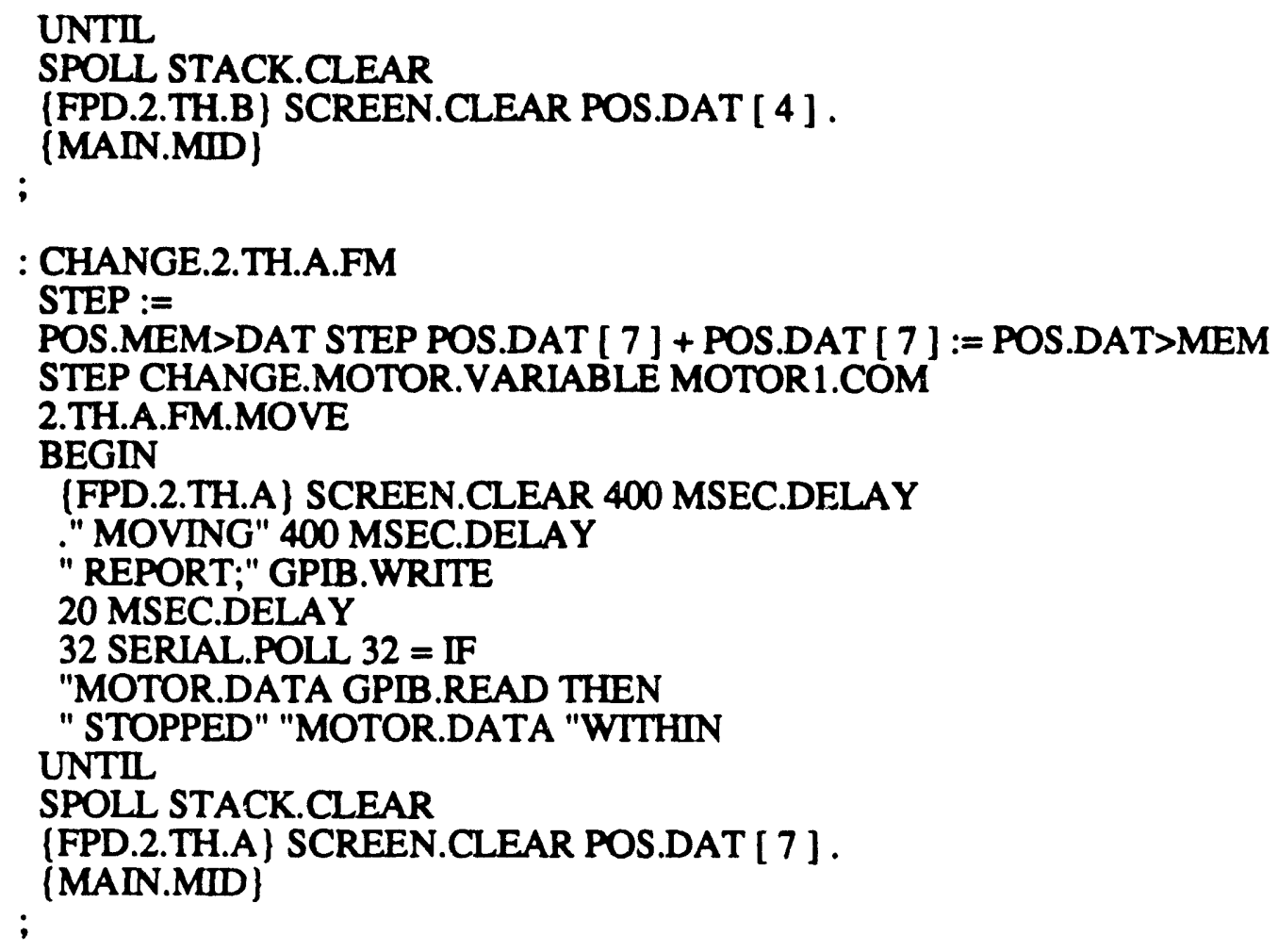

IW.WRD

IPROGRAMS TO CONTROL THE INCHWORM MOTORS

: IW.READ

IW

BEGIN

"IW.DATA GPIB.READ

I CR "IW.DATA "TYPE

" >" "IW.DATA "WITHIN

UNTIL

STACK.CLEAR

;

: IW.COM

IW

13 EOS.CHARACTER

GPIB.WRITE

2500 MSEC.DELAY

IW.READ

;

: IW.DISPLAY

IW

13 EOS.CHARACTER

GPIB.WRITE 2500 MSEC.DELAY "IW.DATA GPIB.READ 


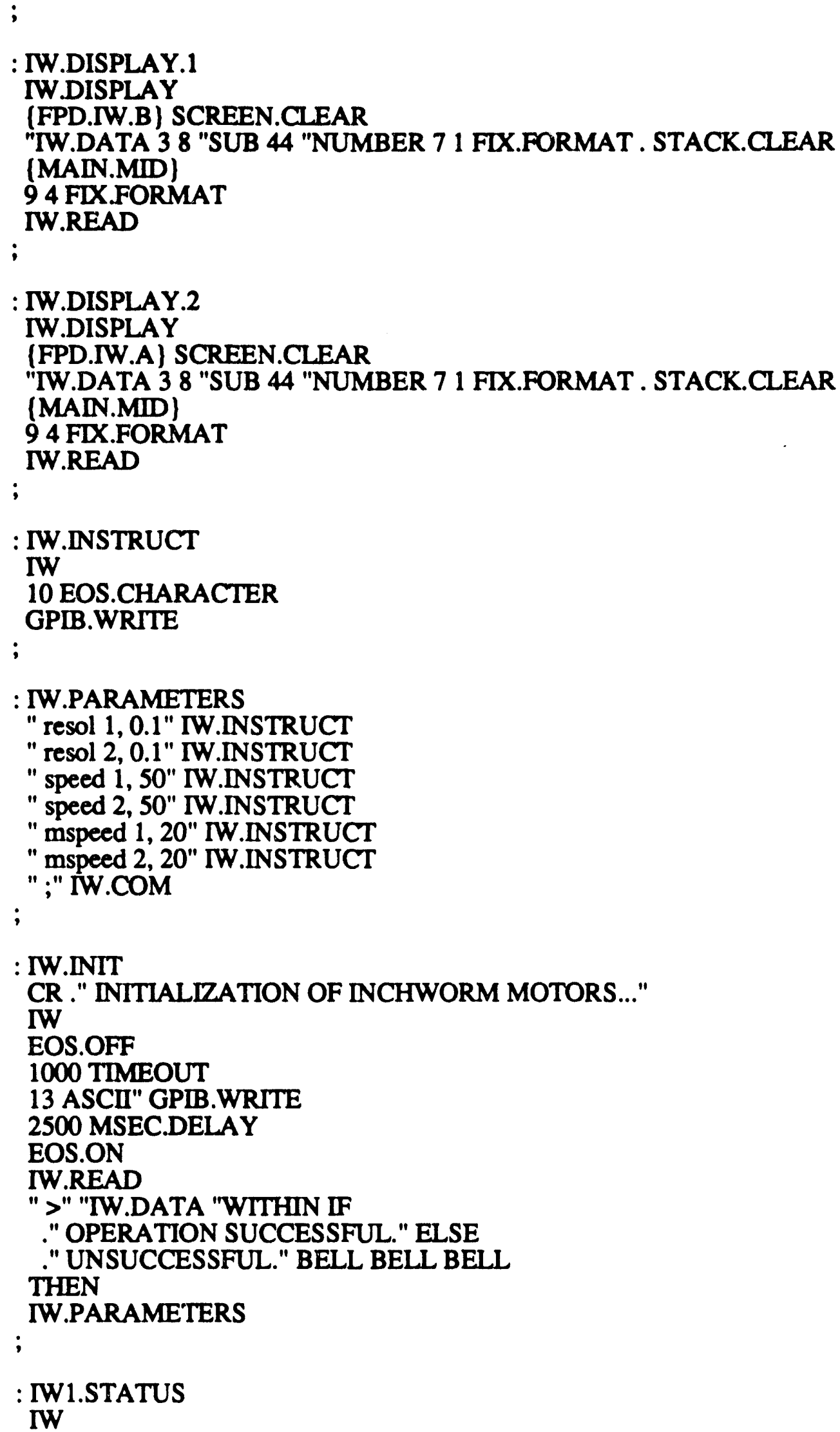




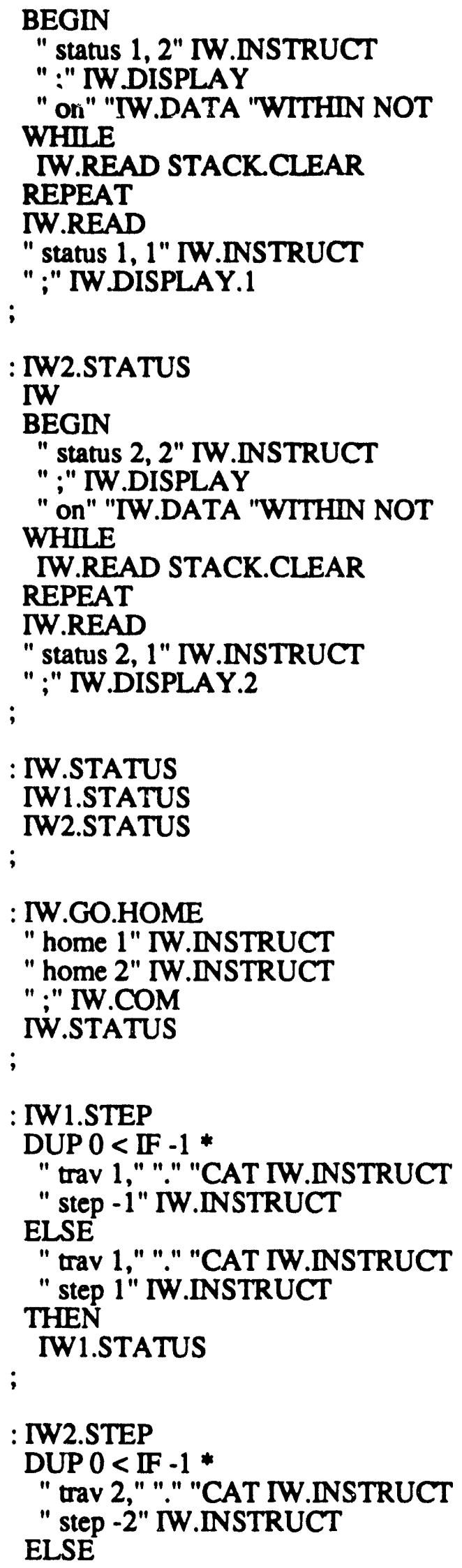




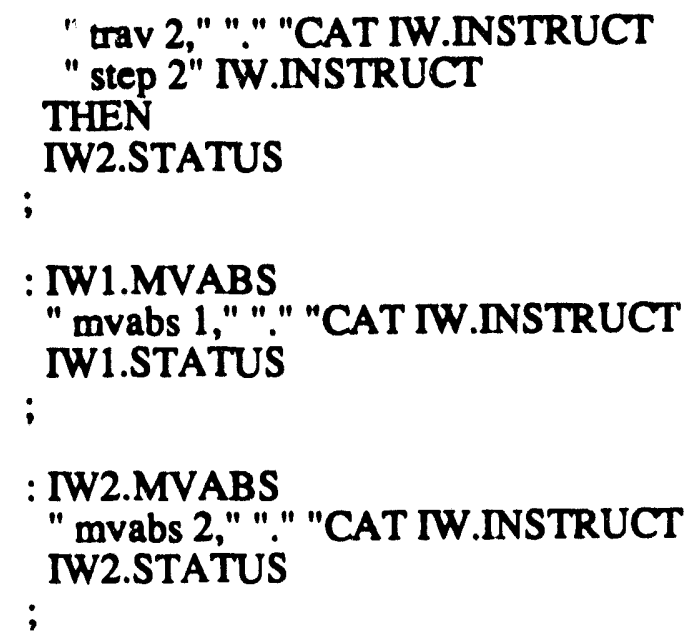

MANNTCAMWRD

IPROGRAM FOR OPERATING THE CAMAC CRATE

\REAL DIM[ 3000 ] ARRAY XX (MAINLOAD.UTL)

IREAL DIM[ 3000 ] ARRAY YY (MAINLOAD.UTL)

INTEGER DIM[ 2 ] ARRAY DF

INTEGER DIM[ 3 ] ARRAY [FAND2

INTEGER DIM[ 2 ] ARRAY [INBUF

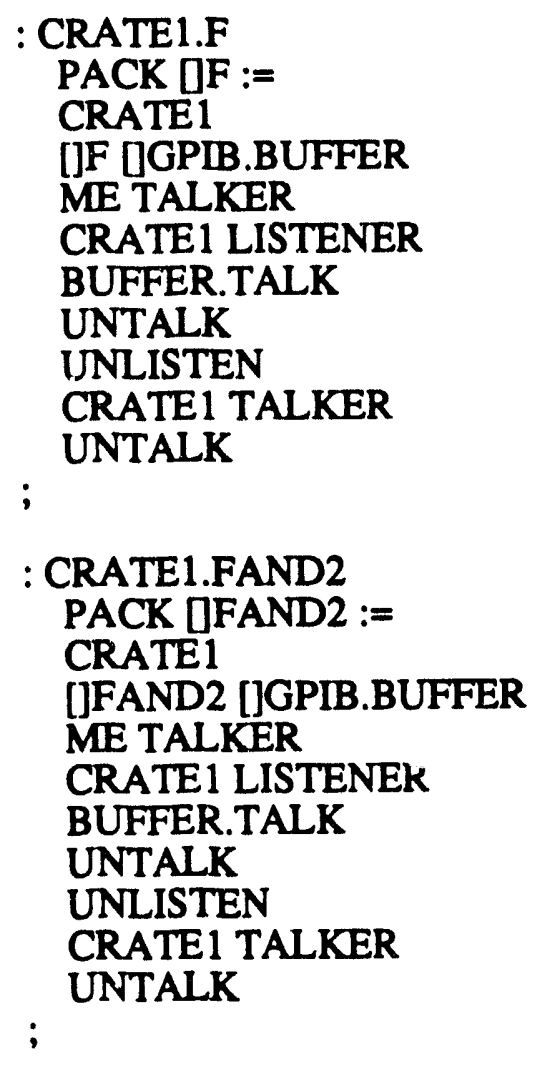




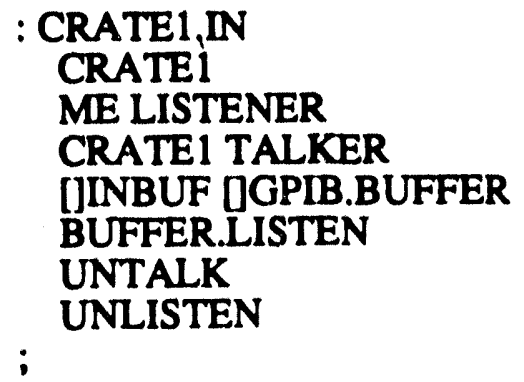

INTEGER DIM[ 3 ] ARRAY WARY 4

INTEGER DIM[ 5 ] ARRAY WARY6

INTEGER DIM[ 5 ] ARRAY DET

INTEGER DIM[ 1 ] ARRAY WARY2

INTEGER DIM[ 1 ] ARRAY TEST1

INTEGER DIM[ 2 ] ARRAY TEST2

INTEGER SCALAR HV 0 HV :=

INTEGER SCALAR NHV

INTEGER SCALAR HV1

INTEGER SCALAR HV2

REAL SCALAR V/SEC

REAL SCALAR VCORR

IPROGRAM TO PROVIDE MAINT. MODE GPIB-CAMAC FUNCTIONS

: MAINT.FAN

CR ." F - Function Code ?" \#INPUT WARY4 [ 1 ] :=

CR ." A - Subaddress ?" \#INPUT WARY4 [2]:=

CR ." N - Station Number? " "INPUT WARY4 [ 3 ] :=

WARY4 CRATE1.F

CR ." OK "

: CAMAC.INIT

16 WARY6 [ 1$]:=$

7 WARY6 [ 2]:=

8 WARY6 $[3]:=$

0 WARY $6[4]:=$

0 WARY $6[5]:=$

WAR Y6 CRATE1.FAND2

." INITIALIZATION OF CRATE1...

BEGIN 127 SERIAL.POLL 3 = UNTIL

. OPERATION SUCCESSFUL." CR

;

: MAINT.FAND2

CR ." F - Function Code ? " \#INPUT WARY6 [ 1 ] :=

CR ." A - Subaddress ? " \#INPUT WARY6 [2]:=

CR ." N - Station Number? " \#INPUT WARY6 [ 3] :=

CR." Enter Data " "INPUT TEST1 :=

TEST1 UNPACK

TEST2 :=

TEST2 [ 1 ] WARY6 [ 4] :=

TEST2 [ 2 ] WARY $6[5]:=$

WARY6 CRATE1.FAND2 
: SET.DET.HV

16 DET [ 1 ]:=

CR ." A - Subaddress ? " \#INPUT DET [ 2 ] :=

CR ." N - Station Number ? " \#INPUT DET [ 3 ] :=

CR ." Counter High Voltage (Volts) " \#INPUT 1.05 / NHV :=

NHV HV DO

I TEST1 :=

TEST1 UNPACK

TEST2 :=

TEST2 [ 1 ] DET [ 4]:=

TEST2 [ 2 ] DET [ 5$]:=$

DET CRATE1.FAND2

20 MSEC.DELAY

NHV HV > IF 1 ELSE -1 THEN +LOOP

NHV HV :=

CR ." OK "

;

: READ.ADC

\READS ADC CHANNEL 0

28 WARY $4[1]:=$

0 WARY4 [2]:=

10 WARY $4[3]:=$

WARY4 CRATE1.F

0 WARY4 [1]:=

0 WARY4 [2]:=

10 WARY $4[3]:=$

WARY4 CRATE1.F

CRATE1.IN

[]INBUF [ 1 ]

BEGIN 127 SERIAL.POLL 3 = UNTIL ;

: READ.ADC1

28 WARY4 [ 1$]:=$

1 WARY4 [2]:=

10 WARY $4[3]:=$

WARY4 CRATE1.F

0 WARY4 [1] :=

1 WARY4 [ 2$]:=$

10 WARY $4[3]:=$

WARY4 CRATE1.F

CRATE1.IN

[]INBUF [ 1 ]

BEGIN 127 SERIAL.POLL 3 = UNTIL

;

: MAINT.F

CR ." F - Function Code ? " \#INPUT WARY2 [ 1 ] :=

WARY2 CRATE1.F

;

ECHO.OFF 


\section{MENUWRD}

I Program for displaying the main menu and loading operational subprograms

I" SET ROI 2000, 5000" ORTEC.COM

REAL SCALAR BETA

INTEGER SCALAR CHARGE

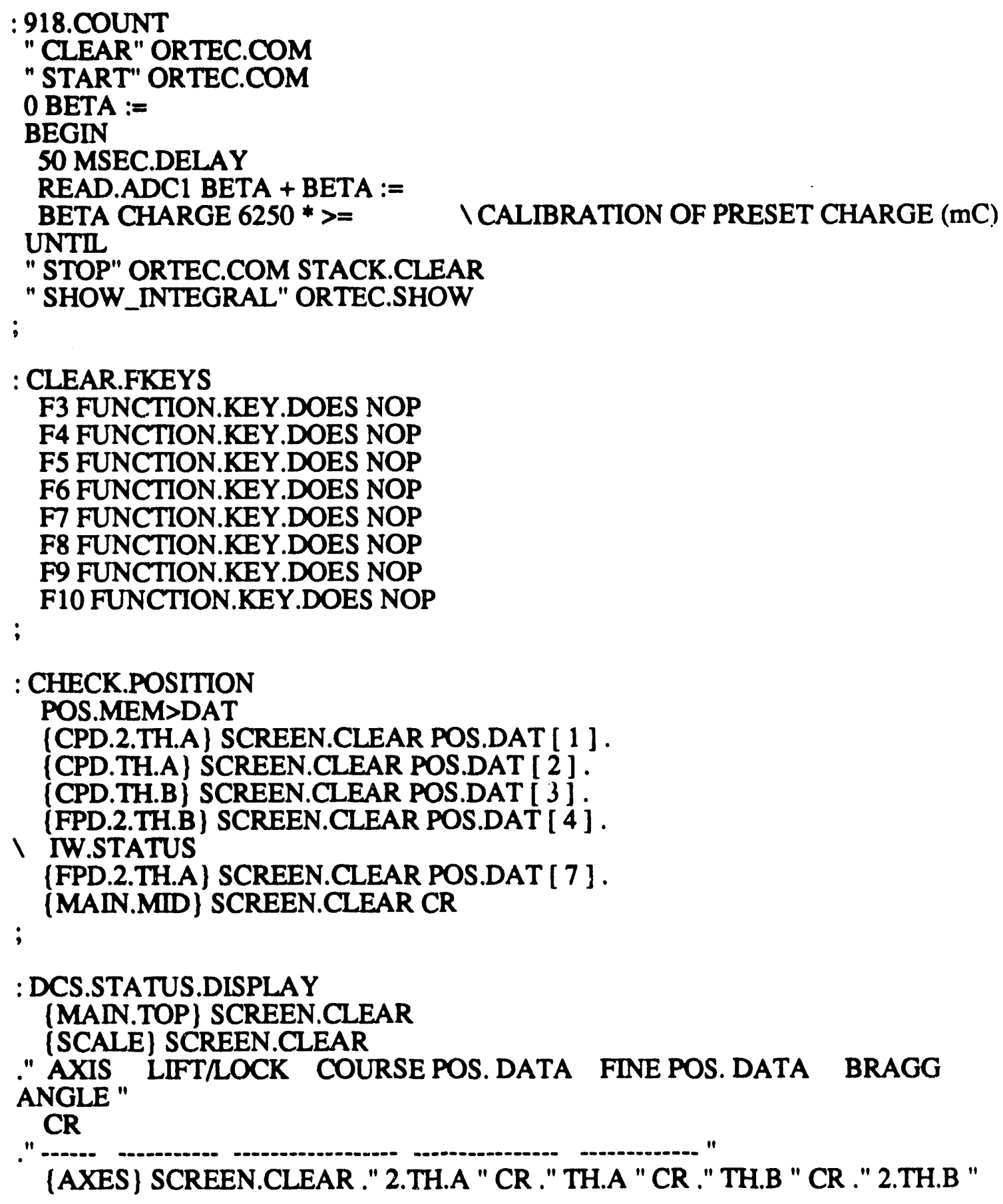

. AXIS LIFT/LOCK COURSE POS. DATA FINE POS. DATA BRAGG ANGLE " 


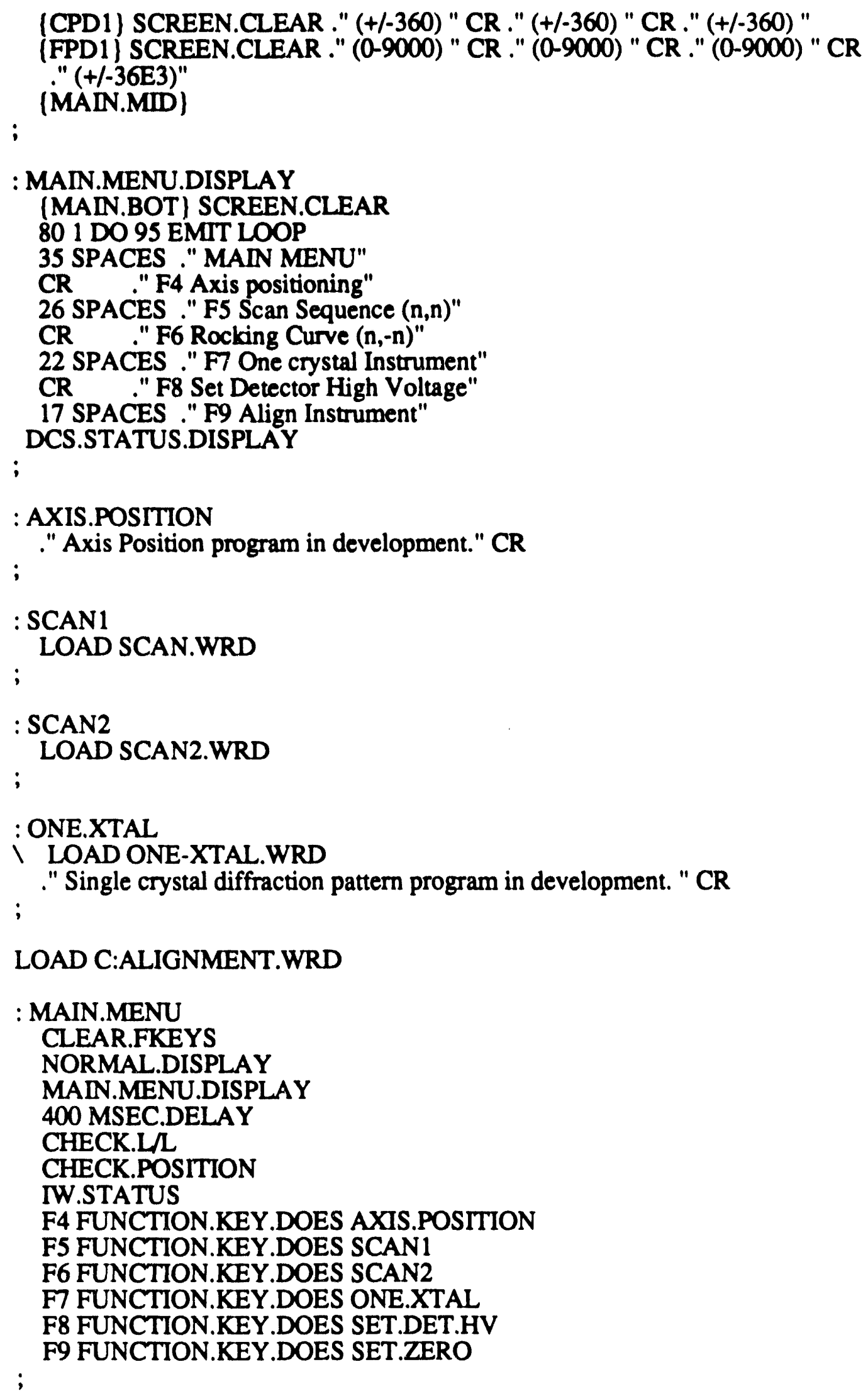


F3 FUNCTION.KEY.DOES MAIN.MENU

CR ." Hit F3 to Display the Main Menu."

ECHO.ON

ALIGNMENT.WRD

IPROGRAMS TO ALIGN THE DCS

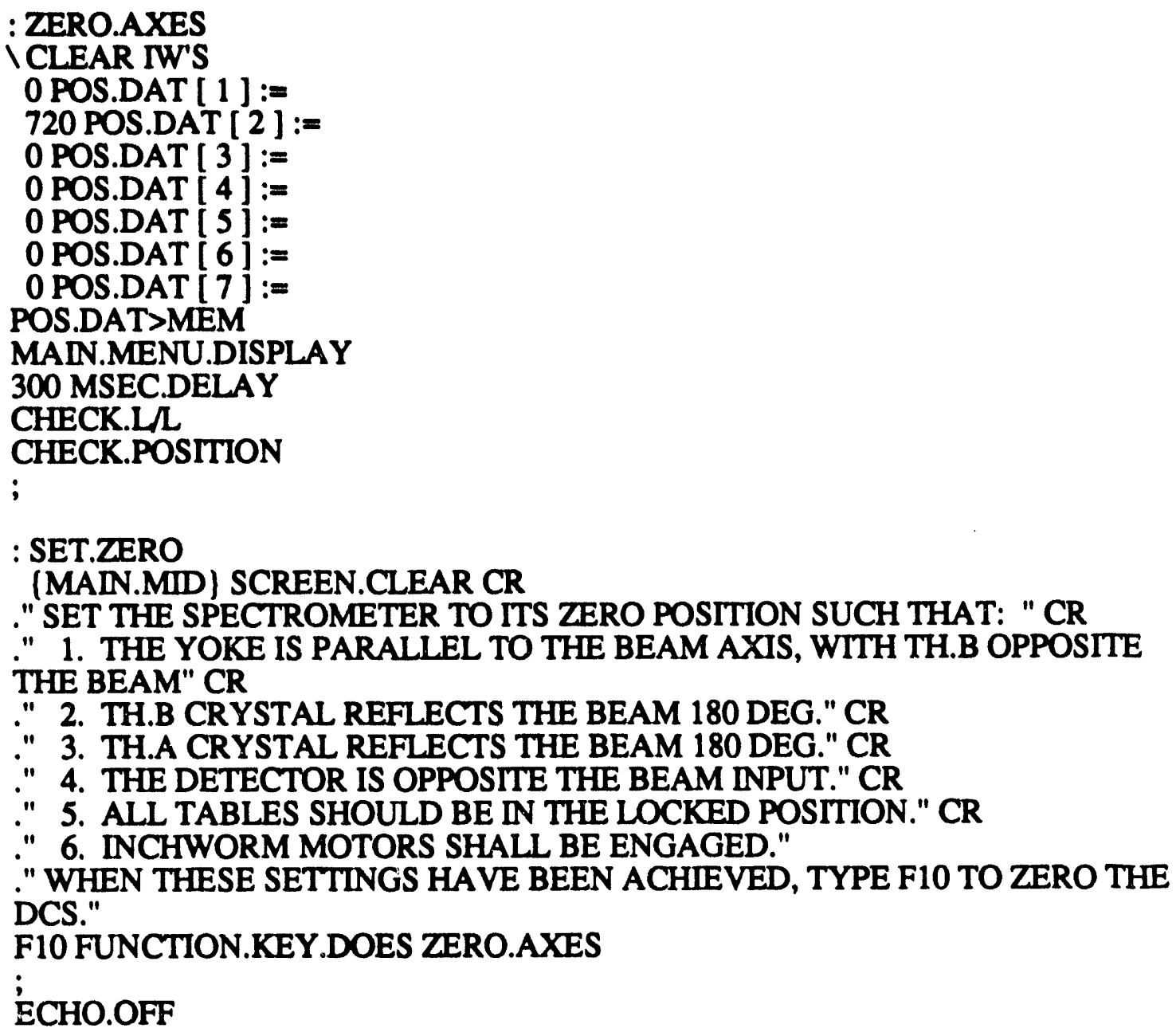

SCAN.WRD

ISCAN.WRD IS A PROGRAM FOR OPERATING THE DCS IN VARIOUS SCAN MODES

REAL SCALAR BRAGG1

REAL SCALAR BRAGG2

REAL SCALAR BRAGG1.SEC

REAL SCALAR BRAGG2.SEC

REAL SCALAR DEL.TH

REAL SCALAR ALPHA 


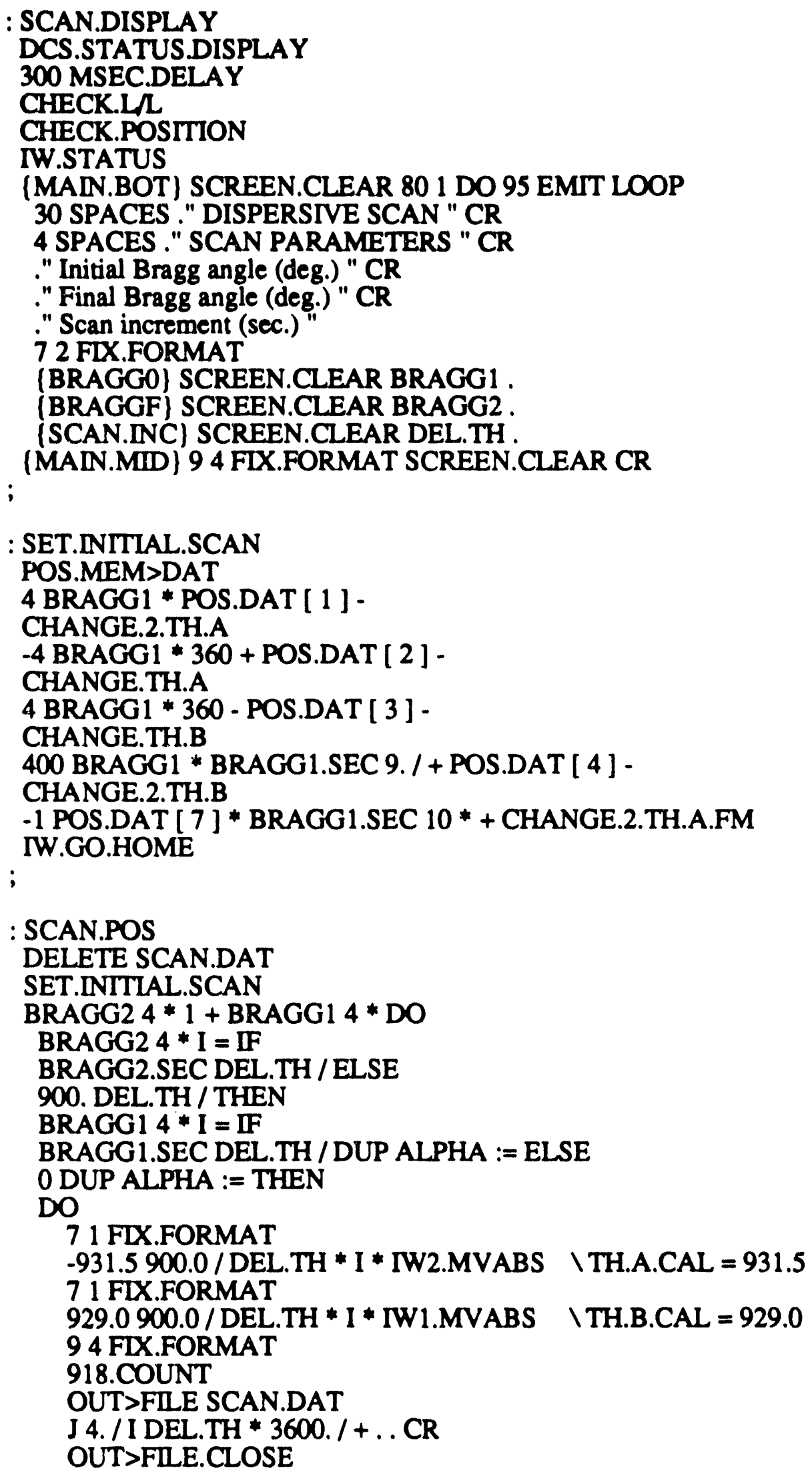




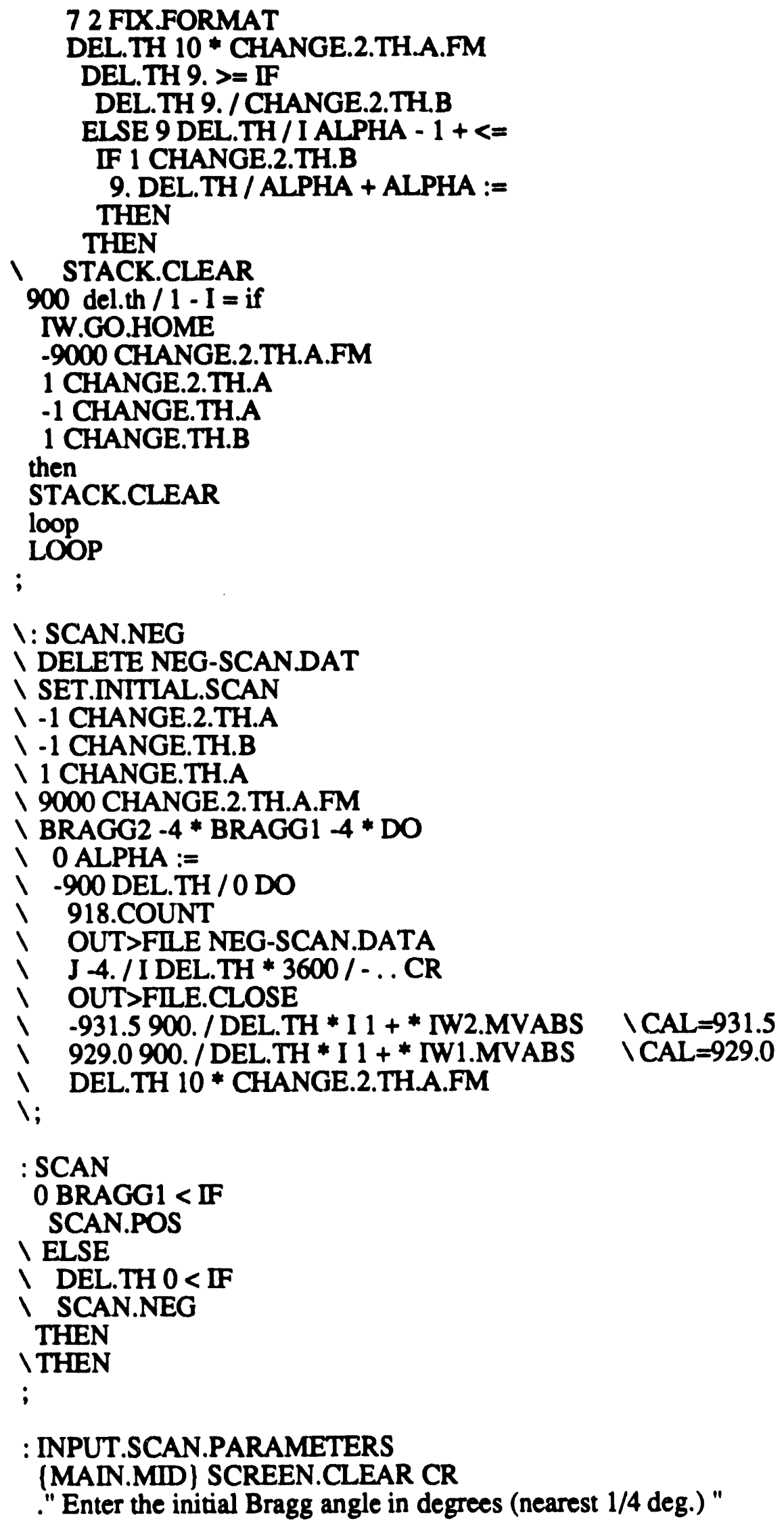




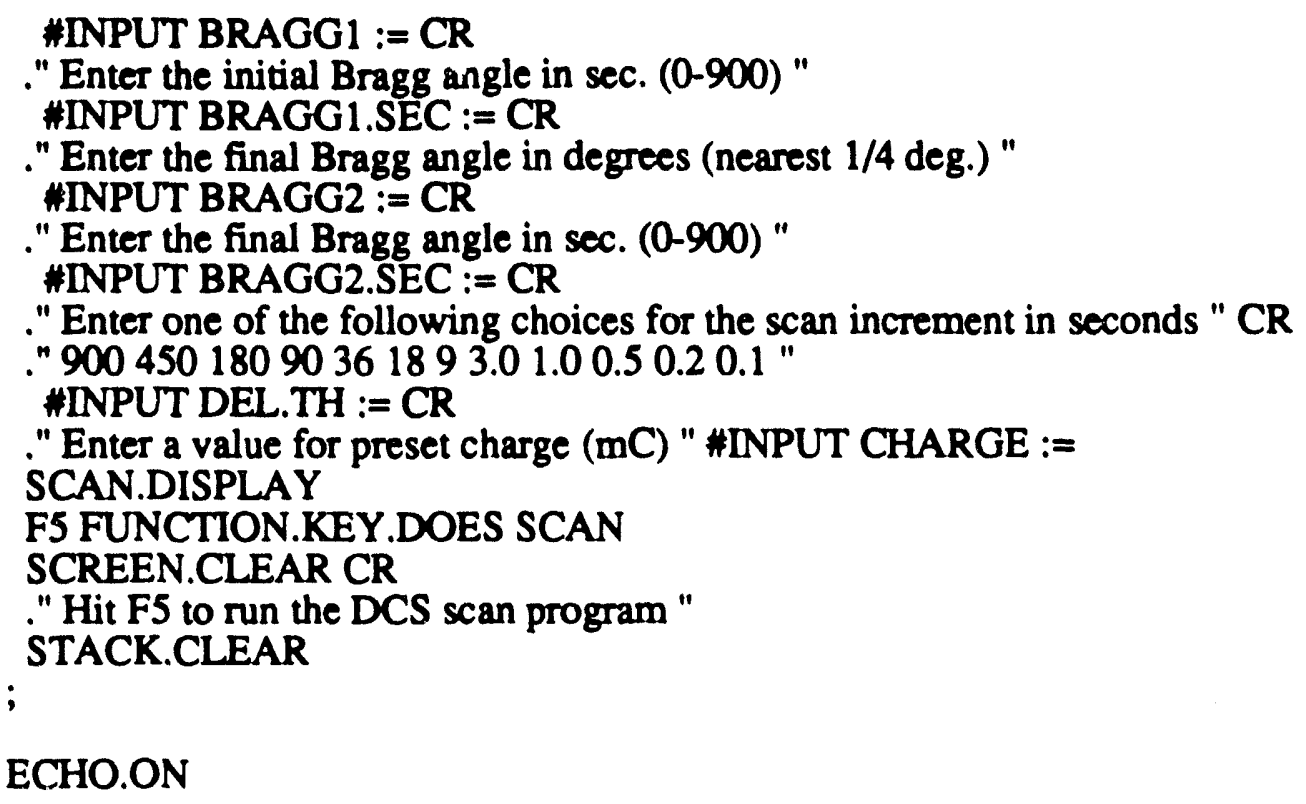

INPUT.SCAN.PARAMETERS

SCAN2.WRD

ECHO.OFF

I SCAN2.WRD IS A PROGRAM FOR OBTAINING DCS ROCKING CURVES

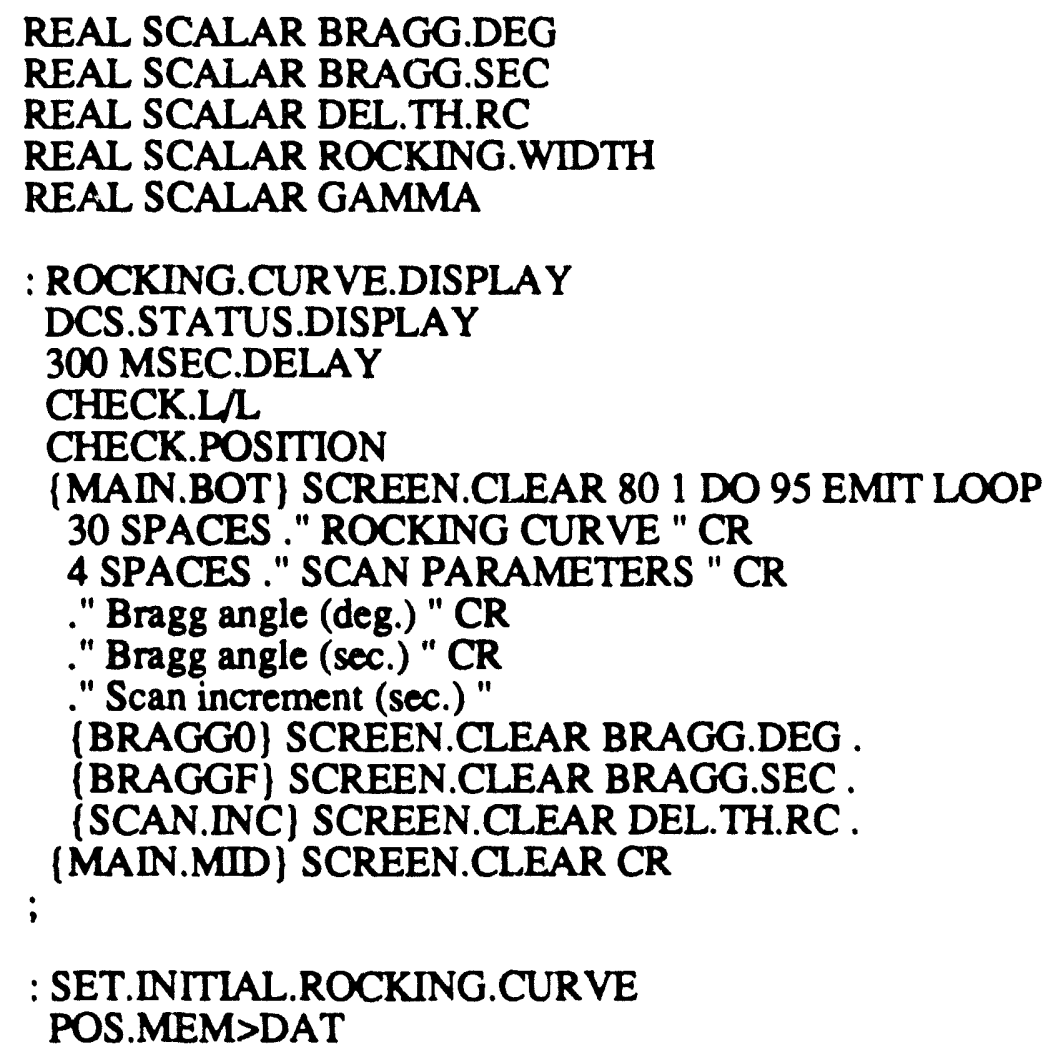




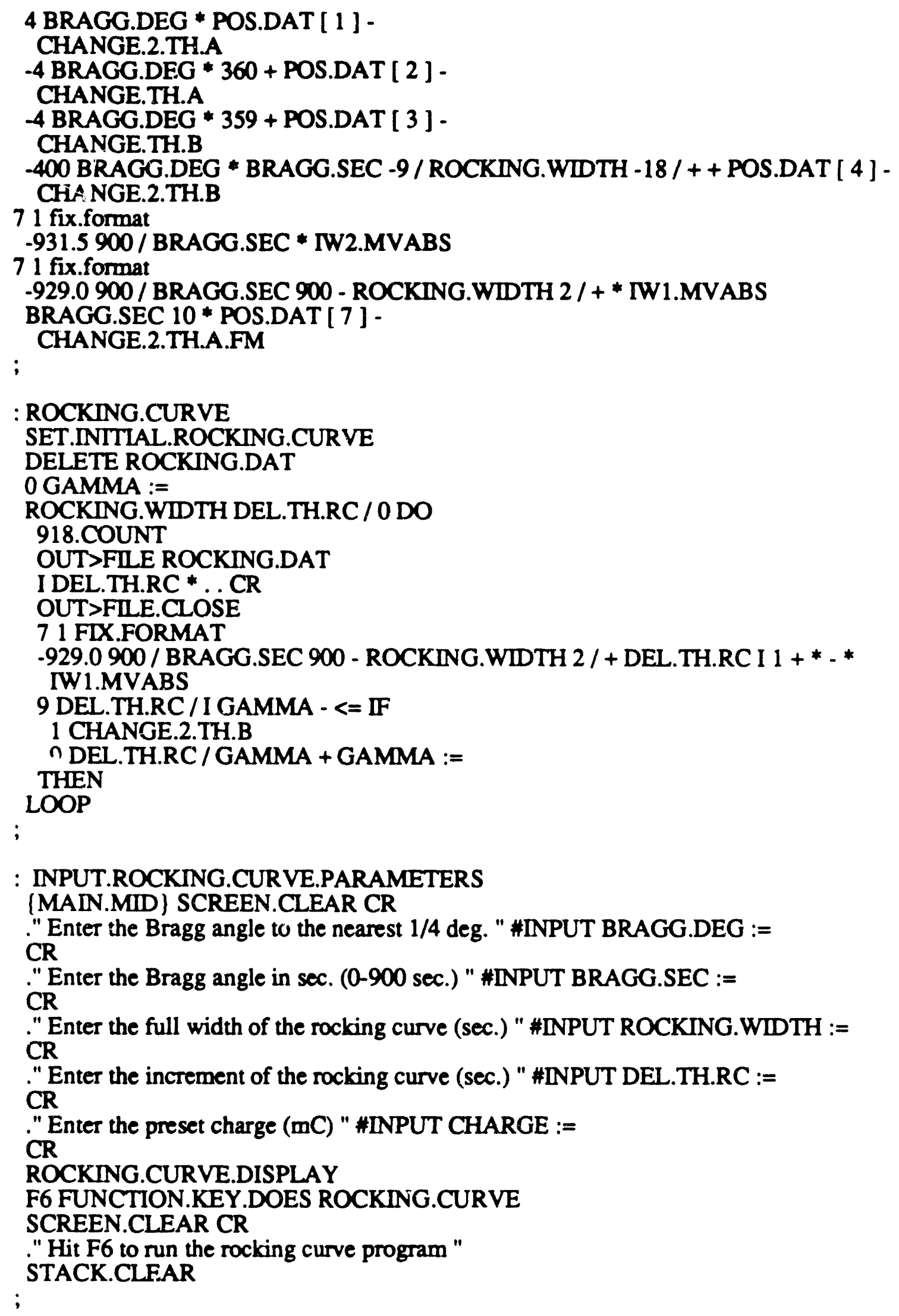




\section{ECHO.ON}

INPUT.ROCKING.CURVE.PARAMETERS 


\section{APPENDDX B}

\section{PROGRAMMING WORD LIST}

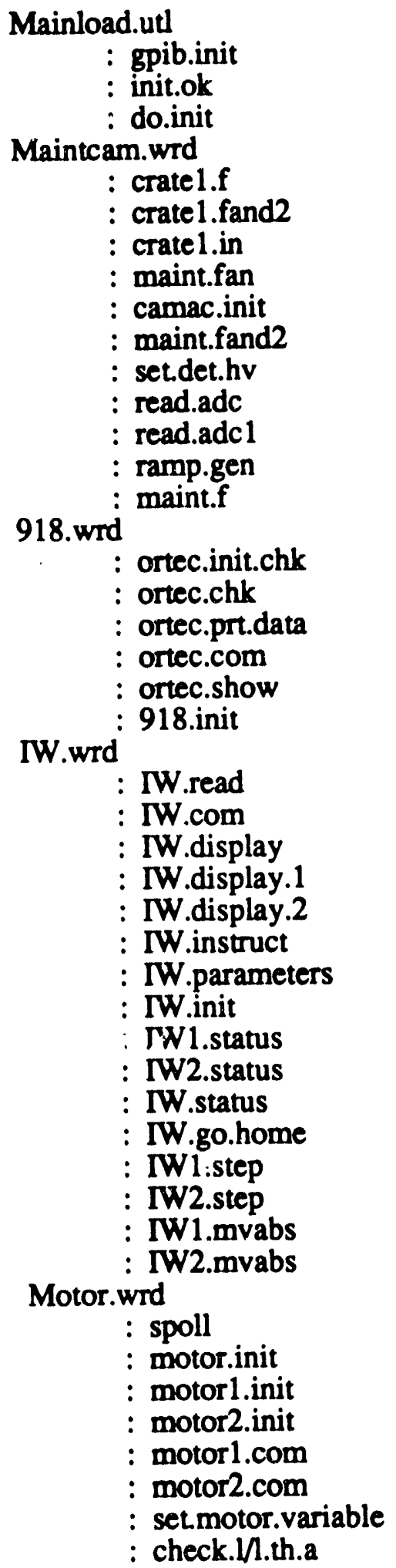




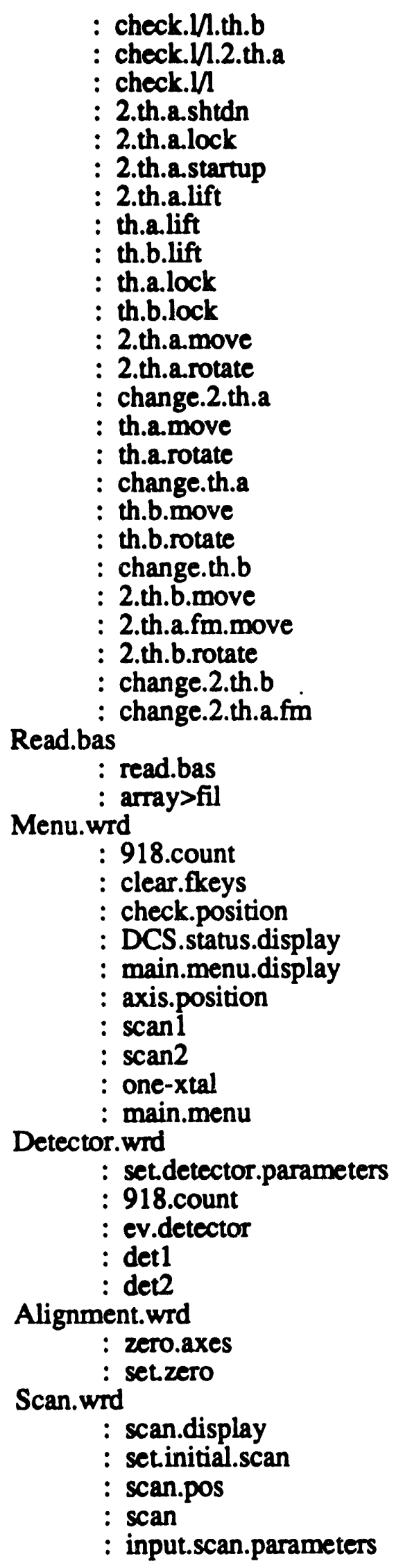


- 1

Scan2.wrd

: rocking.curve.display

: set.initial.rocking.curve

: rocking.curve

: input.rocking.curve.parameters 

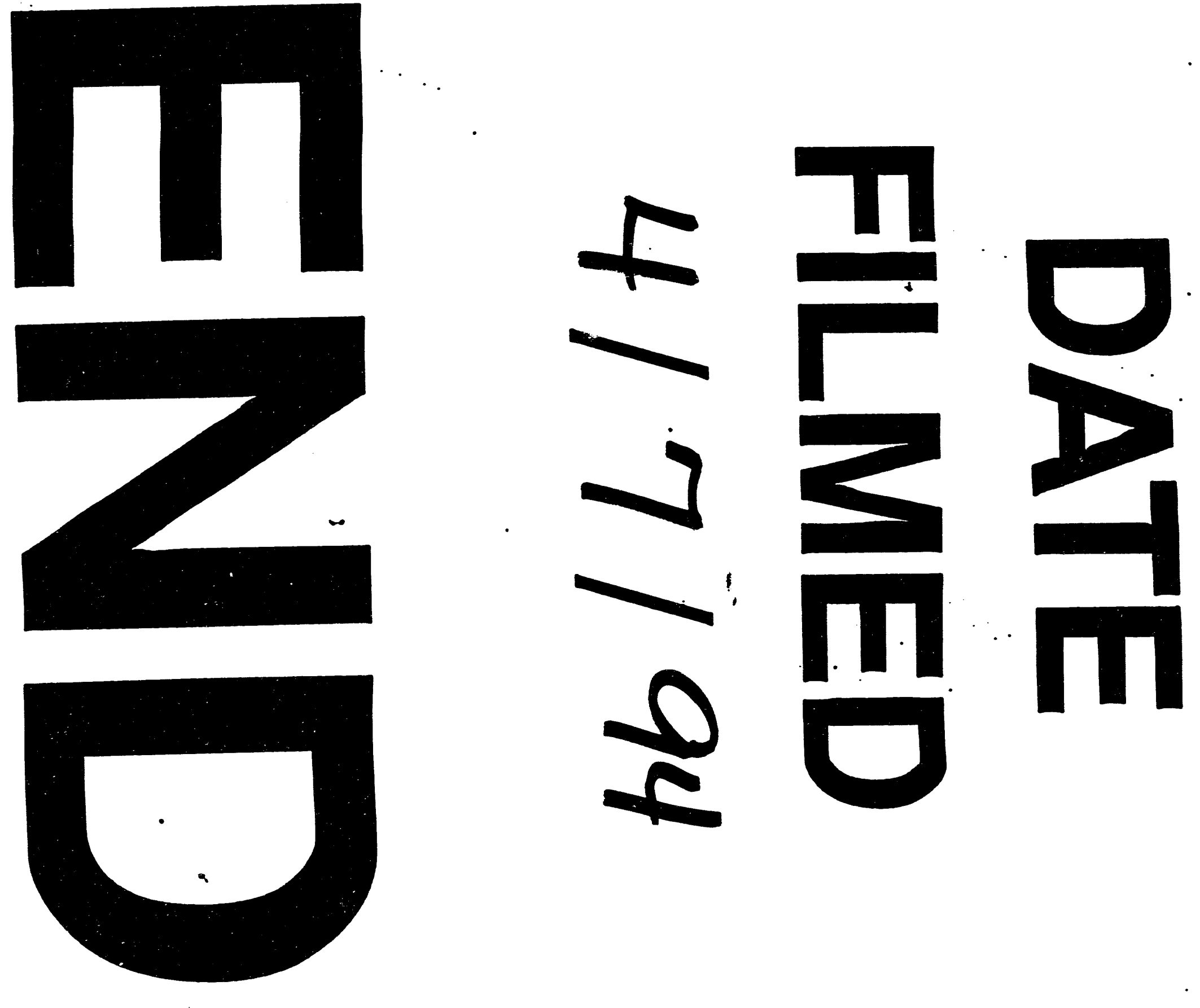


$$
\text { ב- }
$$

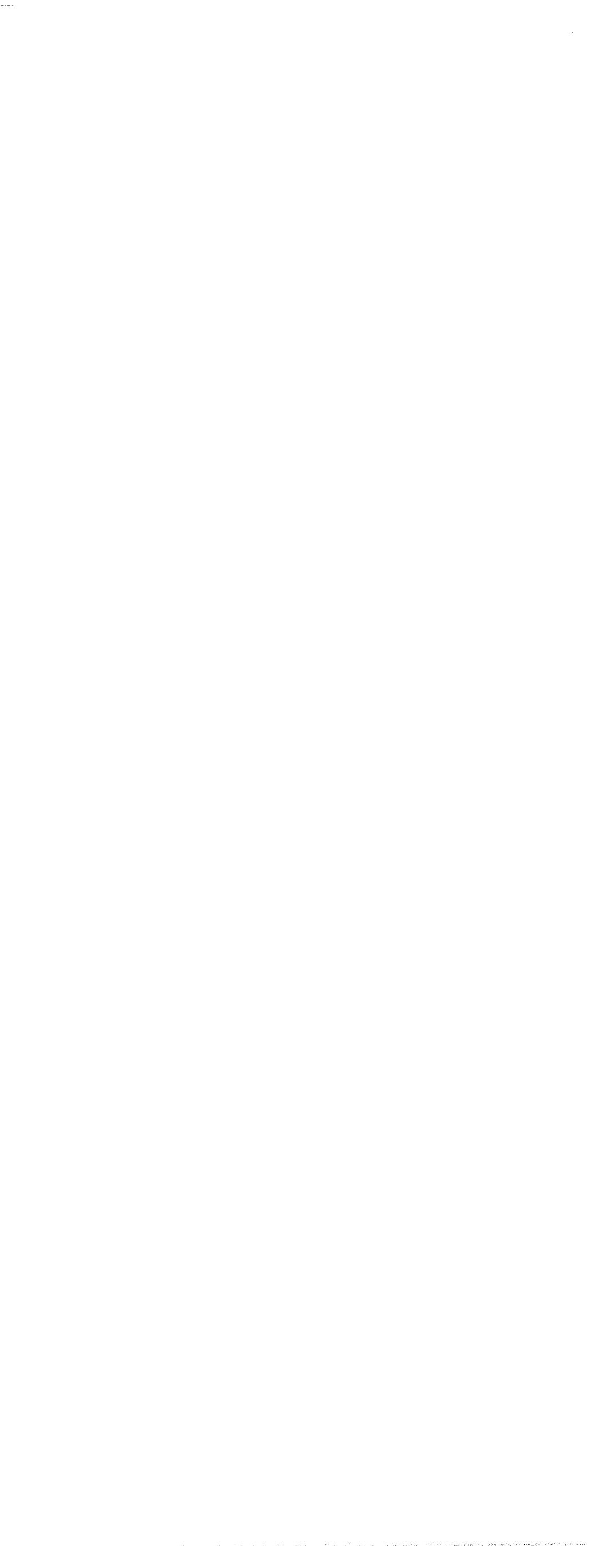

